\title{
It is Hobbes, not Rousseau: an experiment on voting and redistribution
}

\author{
Antonio Cabrales · Rosemarie Nagel · \\ José V. Rodríguez Mora
}

Received: 8 September 2009 / Accepted: 10 August 2011

(C) Economic Science Association 2011

\begin{abstract}
We perform an experiment which provides a laboratory replica of some important features of the welfare state. In the experiment, all individuals in a group decide whether to make a costly effort, which produces a random (independent) outcome for each one of them. The group members then vote on whether to redistribute the resulting and commonly known total sum of earnings equally amongst themselves. This game has two equilibria, if played once. In one of them, all players make effort and there is little redistribution. In the other one, there is no effort and nothing

We thank Iris Bohnet, Tim Cason, David Cooper, John Duffy, Maia Guell, John Van Huyck and Robin Mason for helpful conversations and encouragement. The comments of the Editor and two referees helped improve the paper. We gratefully acknowledge the financial support from Spain's Ministry of Science and Innovation under grants CONSOLIDER INGENIO 2010 CSD2006-0016 (all authors), ECO2009-10531 (Cabrales), ECO2008-01768 (Nagel) and the Comunidad de Madrid under grant Excelecon (Cabrales), the Generalitat de Catalunya and the CREA program (Nagel), and project SEJ2007-64340 of Spain's Ministerio de Educación y Ciencia (Rodríguez Mora).
\end{abstract}

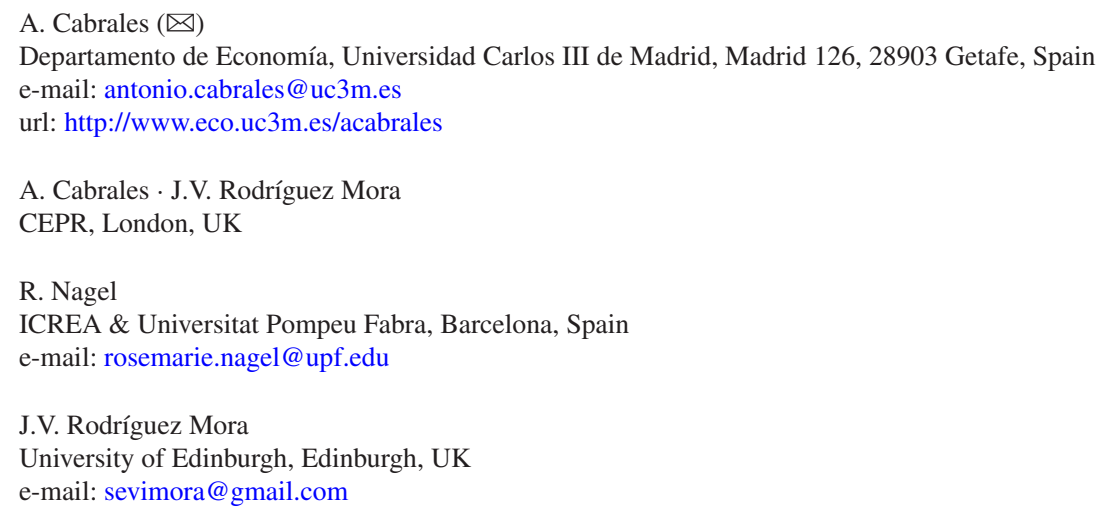


to redistribute. A solution to the repeated game allows for redistribution and high effort, sustained by the threat to revert to the worst of these equilibria. Our results show that redistribution with high effort is not sustainable. The main reason for the absence of redistribution is that rich agents do not act differently depending on whether the poor have worked hard or not. The equilibrium in which redistribution may be sustained by the threat of punishing the poor if they do not exert effort is not observed in the experiment. Thus, the explanation of the behavior of the subjects lies in Hobbes, not in Rousseau.

Keywords Redistribution · Political equilibrium · Voting · Multiple equilibria · Experiments

JEL Classification $\mathrm{C} 72 \cdot \mathrm{C} 92 \cdot \mathrm{D} 72 \cdot \mathrm{E} 24 \cdot \mathrm{H} 24 \cdot \mathrm{I} 31 \cdot \mathrm{O} 38$

\section{Introduction}

The welfare state is viewed as a remarkable achievement of modern societies. It is credited with large reductions of poverty in developed countries (see e.g. Moller et al. 2003). ${ }^{1}$ It certainly eases the pain of negative shocks to income and utility coming from cyclical involuntary unemployment, health problems and even structural economic changes that leave the skills of some members of society outdated. It is obvious, at the same time, that this reduction of uncertainty can come accompanied by large negative effects on incentives to exert productive effort in different dimensions. It lowers the incentives of the unemployed to look for jobs, to work when minor health afflictions arise, to maintain human capital up to date, or to choose judiciously the line of business in which to work (Atkinson 1995). ${ }^{2}$

The welfare state can thus serve as a form of social insurance. The negative incentive effects of any kind of insurance are known as "moral hazard". But, unlike in private insurance, redistribution from the "lucky" to the "unlucky" in social insurance is not done through some kind of ex-ante contract, but through voting. And at the time of voting, individuals already know the cards that economic life has dealt them. In the short run they can vote, if "poor," to appropriate resources from the "rich," or, if "rich," to avoid this expropriation. All this without even taking into account the negative effects on incentives of this purely redistributive conflict, or the insurance value of redistribution.

The pessimistic depiction of voting about redistribution expressed in the previous paragraph is what we will call the Hobbesian point of view. To this view, we also oppose a Rousseaunian perspective. The negative incentive effects of the welfare

\footnotetext{
1 "Researchers have found that the size of the welfare state (for example, as measured by spending on social programs) is a key determinant of poverty reduction," Moller et al. (2003) p. 1.

${ }^{2}$ This was clear even to the predecessor of the modern welfare state, the Poor Laws of the 1830s. They were based explicitly on the twin principles that relief to poverty should be provided in the workhouse and that the poor should not be better off without work than at work. In the words of Porteous (1783): "every person on charity should descend at least one step below the station which he occupied in the season of health and labor."
} 
state on incentives do not have to happen, even in a world of selfish and forwardlooking agents. They can engage in a beneficial social contract where redistribution and high effort are not incompatible. That social contract is possible precisely because the Hobbesian world exists. In such world, any "sucker" who made effort would be exploited by the "wise guys" who would free-ride on the efforts of others, and would vote themselves into sharing the returns from their effort. The Hobbesian world can become the "credible" punishment that gives incentives for all individuals to work hard, and redistribute only to insure against economic shocks that occur "through no fault of their own." But the fact that the Rousseaunian perspective is an equilibrium possibility does not mean that it will occur, given that the Hobbesian world is also an equilibrium.

Given that theory does not provide too much guidance in problems of equilibrium selection, and given the difficulty of field testing any theory with multiple equilibria, we decided to conduct a laboratory experiment to sort out the different possibilities empirically. In the experiment, all individuals in a group decide whether to make a costly effort. ${ }^{3}$ If they choose high effort, the individual outcome is a high level of income with probability $2 / 3$ and a low level of income with the complementary probability. If they choose low effort, income is low for sure. The group members then vote on whether to redistribute equally the total income of the group (without deducting the cost of effort). This design intends to mimic the features of the (admittedly stylized) welfare state we have been discussing above, and giving the Rousseaunian "social contract" a fair chance of working. To this end, for example, the group is kept relatively small, with only nine players, and the aggregate effort is observed every period before voting and repeating the game. This is the environment we could think of where a "social contract" equilibrium has an easiest chance to appear. At the same time, it is sufficiently rich so that the incentive problems associated with the welfare state are also possible.

Indeed, when played only once (in a static framework) the game we just described has two equilibria. This is perhaps a surprise, as the traditional view tends to make the possibility of the welfare state an apocalyptic threat on honest effort. To understand the equilibrium structure, first notice that, in the static game, it is weakly dominant for the individuals with high income to vote against redistribution and for the individuals with low income to vote in its favor. Anticipating this, the players face a sort of coordination game. If all of them make effort, it is quite likely that most of them will be rich (and there will be no redistribution), so as long as expected utility of the extra output created from the high effort compensates the cost, they are prepared to do it. On the other hand, if no one makes an effort, most people will have low output with certainty, so a lone player contributing high effort will see most of its proceeds taken away from him. These two equilibria are Pareto-ranked, with the one with high effort being more efficient. ${ }^{4}$

In the repeated game, redistribution with high effort is sustainable during most of the game, even if there is a finite number of repetitions. The "social contract" equilibrium establishes that up until the last few periods players should make effort and vote

\footnotetext{
${ }^{3}$ Except in one of the treatments.

${ }^{4}$ Remember that no effort-no income is a possible choice in the all-effort equilibrium. If it is not chosen, it must be because the players prefer to make costly effort and obtain a random level of income.
} 
for redistribution. As long as that happens, the last few periods are characterized by the high-effort no-redistribution static equilibrium. Any deviation from the equilibrium path is "punished" by reversion to the no-effort equilibrium. This is a credible punishment, as it is a Nash equilibrium of the stage game.

The experimental results show that the Rousseaunian social contract of redistribution with high effort is not sustainable in the laboratory. The few times when we observe redistribution with high effort, it does not last very long. The main reason is that voting behavior does not vary with the observation of different levels of aggregate effort. Furthermore, even the static equilibrium with high effort is fragile. It is sustained to the end of the game in very few groups. More frequently several players start making effort, only to give up later in the game. The no-effort equilibrium, on the other hand, seems quite robust. The worst Hobbesian outcome seems to be the most common fate of our experimental societies. We think this is an important result that shows why in reality the welfare state seems to be constantly under threat, and why societies which see its good effects have to devise complicated mechanisms to keep it in place.

In our main treatment, the rich very seldom vote for redistribution. This could be because they cannot condition their behavior on the reason why each of the poor is poor. We introduced two additional treatments to test further whether rich people would like to have a differential behavior toward those who are poor "through no fault of their own." Thus, in some treatments we changed the voting procedure, either demanding unanimity for redistribution, or excluding non-effort makers from redistribution. These changes make high effort robust and sustainable, but they do not yield redistribution very often. We also include a treatment where there is no effort decision. Income realizations are random and exogenous to the subjects. This is an important control treatment in order to check to which extent voting behavior is influenced by past observations of effort levels.

Our results indicate that agents play political games in a manner which does not punish or reward past actions. Hence, the behavior of our subjects is consistent with the Markov perfect equilibria which are the main focus of the political economy literature, since they do not seem to condition their voting decisions in payoff irrelevant events. In our context this means, for example, that subjects do not condition their effort decision in one period on the outcome of voting and redistribution in the previous period, or they do not condition their vote for redistribution on whether a poor person has made a costly effort or not.

As with all experimental research, there is a question about the external validity of our experimental results. In this respect we would like to point out that as Schram (2005) argues "External validity is relatively more important for experiments searching for empirical regularities than for theory-testing experiments," and quoting Plott (1982), he adds "Plott takes the position that experiments do not need to be realistic so long as they closely implement the theory being tested." Ours is clearly a theorytesting experiment, since we were endeavoring to find out which of the different theoretical possibilities arose in our environment. Furthermore, although the setting is not completely natural, neither is it absolutely artificial. Real people do vote in elections where redistribution is an important consideration. In our setting there is a cost of producing the potential reward that can be redistributed, but this effort does not al- 
ways yield fruit. At a minimum, we believe our results to be to sufficiently suggestive to make a good case for further field testing of the ideas.

\section{Related literature}

The literature has addressed related issues. Lindbeck et al. (1999) suggest that the welfare state breaks down when people start breaking the implicit contract that lies at its root: "you work hard, and if you are unlucky, we will help you." A similar motif can be glanced in the work of Alesina and Angeletos (2005), in this case guided through fairness concerns internalized in the utility function.

Most experimental papers on voting study committee behavior or the paradox of voting (e.g. Fiorina and Plott (1978), Schram and Sonnemans (1996)). There are a few voting experiments related to ours. Many papers study the problem of voting in the context of contribution in public good games with only one equilibrium. Sutter and Weck-Hannemann (2004), for example, show that players contribute less if there is a minimum compulsory level of contribution which is determined through voting. Sutter et al. (2010), also in a public good experiment, give the option to vote about implementing reward or punishment. Subjects vote in favor of rewarding high contributions and obtain a more efficient outcome.

Some papers study voting on redistribution in a context in which a random draw determines whether a player is rich or poor. Thus, Tyran and Sausgruber (2006) show that, in a one shot game, the unique equilibrium with social preferences à la Fehr and Schmidt (1999) predicts voting patterns by rich and poor better than the unique selfinterested Nash equilibrium. Sutter (2002) finds that players show solidarity between them, voting against a public good which would increase total surplus but may harm some players, a behavior which is contradictory with the unique Nash-equilibrium prediction.

There are experiments which endogenize the received income through different effort mechanisms. In experiments by Frohlich and Oppenheimer (1990) the redistribution scheme is determined either exogenously by the experimenters or by the subjects. In the latter case the subjects vote for a redistribution scheme from rich to poor under the veil of ignorance, that is, before knowing one's type and the real effort task to be performed afterward. Then, they receive an income which increases with the number of errors they find in a given text. They find that effort level increases after a transfer is received, if redistribution is decided endogenously. Under exogenously determined scheme this effect is not observed. ${ }^{5}$ One problem with this approach is that at the time of voting subjects do not know whether success is determined through effort, luck or personal characteristics (as skill). In addition using "costly" mouse click task as in our paper instead of real tasks has the advantage of easily disentangling whether increasing or decreasing effort levels can be attributed to changes of effort levels of others, instead of, say, attributing it to learning of the

\footnotetext{
${ }^{5}$ Hoffman and Spitzer (1985) designated a controller through several methods ranging from a random assignment to being the winner of a game of skill. The controller can decide on the distribution of money between himself and others. The distribution varies greatly with the method to choose the controller.
} 
task. In any case, our focus is not as much on the effort level produced given a certain degree of redistribution, as on the voting patterns that we observe once effort levels have been determined. We believe that this approach yields higher returns, as in real life almost everybody votes being aware of their station in life.

Our experiments are also related to the large literature on coordination games as surveyed in Ochs (1995). Van Huyck et al. (1990) show that behavior typically converges to the inefficient outcomes in large groups of players. Long time horizons, however, may induce more efficient outcomes as shown in Berninghaus and Ehrhart (1998). We add to these papers exogenous uncertainty and voting about redistribution.

Our most important contribution is that we provide a link with the theoretic macro-political economy literature. We show that subjects behavior is consistent with Markov equilibria. Payoff irrelevant events, such as last period's voting outcome or the reason why someone is poor, are disregarded by voters, and thus, ethical and moral considerations seem to lay beyond their concern, at least when dealing with redistribution.

\section{The games}

We model a politico-economic game of redistribution where agents choose the policy via a well established voting mechanism once they know their station in life. We depart from the standard macro model (see Hassler et al. 2003, for instance) in only two qualitative respects.

First, we do not have state variables. In this manner we abstract from issues related to rational dynamic voting and from self-reinforcing mechanisms in the determination of political outcomes (multiple steady states as different from multiple equilibria). We focus on whether subjects condition their actions on past behavior in a way which allows for the sustainability of the first best. The experimental study of dynamic rationality is an important item for future research, but the present question is sufficiently important to be studied in isolation.

The second way in which we depart from the standard model is by making our set of voters finite. We do so in order to facilitate the sustainability of the (Rousseaunian) first best equilibrium. If even in this circumstances it is not sustained, it is difficult to conceive how it could be sustained with a realistic (much larger) number of agents.

There are 9 players in each group $\mathcal{N}=\{1,2, \ldots, 9\}$. The game $G$ proceeds in two stages.

In the first stage, each player $i \in \mathcal{N}$ takes a decision on whether to make an effort $e_{i} \in\left\{e^{H}, e^{L}\right\}$. Effort choice $e_{i}=e^{H}$ has a cost $c>0$. Effort choice $e_{i}=e^{L}$ has no cost. The outcome from this effort choice is a random variable $y_{i}$, drawn independently for all players, with $y_{i} \in\left\{y^{H}, y^{L}\right\}$. Its relationship with effort is as follows. When $e_{i}=e^{H}$, then $y_{i}=y^{H}$ with probability $\frac{2}{3}$ and $y_{i}=y^{L}$ with probability $\frac{1}{3}$. When $e_{i}=e^{L}$, then $y_{i}=y^{L}$ with probability 1 . In the second stage, each player $i \in \mathcal{N}$ casts a vote $v_{i} \in\{Y, N\}$. If 5 or more players vote $v_{i}=Y$, then the final income of every player is $y_{i}^{F}=\sum_{j=1}^{n} y_{j} / 9$ (gross of effort costs). If 4 or less players vote $v_{i}=Y$, then the final income of every player is $y_{i}^{F}=y_{i}$ (again, gross of effort 
costs). Before the second stage, the players know the aggregate realization of the true stage: How many are rich or poor, how many put effort and the total sum to distribute (in the design section we go into more details).

The game $G$ is repeated for 50 periods. The repeated game is denoted $\Gamma(G)$.

Let us first analyze theoretically the game $G$.

Let $A$ denote the expected payoff for agent $i$, if all players (including $i$ ) choose to make effort, that is, $e_{i}=e^{H}$. Let also $B$ denote the expected payoff for agent $i$ if all other players $j \neq i$ choose to make effort, that is, $e_{j}=e^{H}$ but player $i$ chooses to make no effort, that is, $e_{i}=e^{L}$. Finally, let $C$ denote the expected payoff for agent $i$ if all other players $j \neq i$ choose to make no effort, that is, $e_{j}=e^{L}$ but player $i$ chooses to make effort, that is, $e_{i}=e^{H}$

Then we have (assuming, as we will show is indeed optimal, that in the second stage the rich players vote $N$ and poor players vote $Y):^{6}$

$C$ is also composed of two terms. The first term is the payoff when there is redistribution and only $i$ made effort, weighted by the probability that $i$ is rich when he is the only one who made effort. The second term is the payoff for being poor weighted by the probability that all are poor ( $i$, who made effort and 8 the others who did not).

$$
\begin{aligned}
& A \equiv \sum_{j=5}^{8}\left(\begin{array}{l}
8 \\
j
\end{array}\right) \frac{2}{3}^{j} \frac{1}{3}^{8-j}\left(\frac{2}{3} u\left(y^{H}-c\right)+\frac{1}{3} u\left(y^{L}-c\right)\right) \\
&+\left(\begin{array}{l}
8 \\
4
\end{array}\right) \frac{2^{5}}{3} \frac{1}{3}^{4} u\left(y^{H}-c\right)+\sum_{j=0}^{4}\left(\begin{array}{l}
8 \\
j
\end{array}\right) \frac{2^{j}}{3} \frac{1}{3}^{9-j} u\left(\frac{\left(y^{H}\right) j+\left(y^{L}\right)(9-j)}{9}-c\right) \\
& B \equiv \sum_{j=5}^{8}\left(\begin{array}{l}
8 \\
j
\end{array}\right) \frac{2}{3}^{j} \frac{1}{3}^{8-j} u\left(y^{L}\right)+\sum_{j=0}^{4}\left(\begin{array}{l}
8 \\
j
\end{array}\right) \frac{2^{j}}{3} \frac{1}{3}^{8-j} u\left(\frac{\left(y^{H}\right) j+\left(y^{L}\right)(9-j)}{9}\right) \\
& C \equiv \frac{2}{3} u\left(\frac{y^{H}+8 y^{L}}{9}-c\right)+\frac{1}{3} u\left(y^{L}-c\right)
\end{aligned}
$$

Proposition 1 The game $G$ has two subgame-perfect equilibria if $A>B$ and $C<$ $u\left(y^{L}\right)$. In one of them $e_{i}=e^{H}$ for all $i \in N$ and in the other one $e_{i}=e^{L}$ for all $i \in N$. In both equilibria, for all $i \in N, v_{i}=Y$ when $y_{i}=y^{L}$ and $v_{i}=N$ when $y_{i}=y^{H}$.

\footnotetext{
${ }^{6} A$ is composed of three terms, all of which consider a situation where all agents beside $i$ make effort. The first term of $A$ indicates the expected payoff for $i$ of making effort when there is no redistribution, weighted by the probability that there is no redistribution because there are at least 5 agents other than $i$ who are rich. The second term of $A$ indicates the payoff when $i$ is rich and there is no redistribution, weighted by the probability that $i$ is rich and exactly 4 agents in addition to $i$ are rich, and the last term of $A$ indicates the expected payoff of redistribution when agent $i$ makes effort, weighted by the probability that there is redistribution because at least 5 agents are poor.

$B$ is composed of two terms, both considering a situation where all the agents beside $i$ made effort. One term is the payoff for $i$ when poor and making no effort, weighted by probability that there are at least 5 rich people, and hence no redistribution. The other is the expected payoff of redistribution for $i$ who made no effort, weighted by the probability that there are at least 5 poor players, including $i$.
} 
Proof See the Appendix A.

Both equilibria exist if players have constant relative risk aversion with an ArrowPratt risk aversion coefficient $r \geq 0.2$. For $r \leq 0.1$, there is only a no effort equilibrium. Notice also that if $r \geq 0.2$, in the equilibrium where all players make effort, this is a strict best-response. That is, even if not all other players made effort for sure, it would still be optimal to make effort. ${ }^{7}$ Most estimates of risk aversion coefficients available in the literature point to values of $r$ well in excess of 0.2. For example. Attanasio et al. (2002) give a GMM point estimate of $r=1.2$ with a standard deviation of 0.5. Hence it seems safe to conclude that the game our subjects played has indeed multiple equilibria.

Now we turn to the repeated game, $\Gamma(G)$. The unconditional repetition of the stage-game equilibria are also equilibria in $\Gamma(G)$. But, when there are two (Paretoranked) equilibria in the state game, we can also look for a third super-game equilibrium in which redistribution might be sustainable. In order to see whether cooperation is sustainable we need to define some more parameters. Let $D$ denote the expected payoff of player $i$ if all other players $j \neq i$ choose to make effort, that is, $e_{j}=e^{H}$ but player $i$ chooses to make no effort, that is, $e_{i}=e^{L}$ and there is redistribution for all realizations of income and $E$ be the expected payoff of $i$, if all players (including $i$ ) choose to make effort, that is, $e_{i}=e^{H}$ of $i$ if all including $i$ choose effort and there is redistribution for all realizations of income:

$$
D \equiv \sum_{j=0}^{8}\left(\begin{array}{l}
8 \\
j
\end{array}\right) \frac{2^{j}}{3} \frac{1}{3}^{8-j} u\left(\frac{\left(y^{H}\right) j+\left(y^{L}\right)(9-j)}{9}\right)
$$

and

$$
E \equiv \sum_{j=0}^{9}\left(\begin{array}{l}
9 \\
j
\end{array}\right) \frac{2}{3}^{j} \frac{1}{3}^{9-j} u\left(\frac{\left(y^{H}\right) j+\left(y^{L}\right)(9-j)}{9}-c\right)
$$

Then we have:

Proposition 2 The repeated game $\Gamma(G)$ has a (Rousseaunian) equilibrium with effort and redistribution. More precisely, let $K$ such that

$$
D-E<K\left(A-u\left(y^{L}\right)\right)
$$

The game $\Gamma(G)$ has a subgame-perfect equilibrium where in the equilibrium path in periods $t=1$ through $50-K-1, e_{i}=e^{H}$ and $v_{i}=Y$, for all $i \in N$.

Proof See the Appendix B.

This equilibrium exists if players have constant relative risk aversion with an Arrow-Pratt risk aversion coefficient $r \geq 0.3$ and the necessary $K$ in this case is $K=2$.

\footnotetext{
${ }^{7}$ How many and how far they can go until it is not optimal any more depends on the parameters.
} 


\subsection{Equilibrium with social preferences}

Although the repeated game $\Gamma(G)$ has an equilibrium where agents both choose to make effort and redistribution, it would be legitimate to ask if there are other circumstances in which one could expect a Rousseaunian equilibrium. This is indeed the case if subjects have preferences which take into account the material payoff of other players. Suppose, for example, that players are as in Fehr and Schmidt (1999). That is, let $u_{i}$ be the expected material payoff of player $i$ in the game. Then, total preferences for player $i$ (including the "social preferences") are:

$$
U_{i}=u_{i}-\frac{\alpha}{N-1} \sum_{j \neq i} \max \left\{\left(u_{j}-u_{i}\right), 0\right\}-\frac{\beta}{N-1} \sum_{j \neq i} \max \left\{\left(u_{i}-u_{j}\right), 0\right\}
$$

With these preferences, it is easy to show that poor agents still want to vote for redistribution. Rich agents vote for redistribution (for all income realizations in the group) if they are sufficiently risk averse and have strong enough social preferences. For example, if they have constant relative risk aversion and their Arrow-Pratt coefficient $r \geq 0.5$, and the Fehr and Schmidt (1999) coefficient $\beta \geq 0.8$. With those same preferences, there would be an all-effort equilibrium as well as a no-effort equilibrium. In the all-effort equilibrium there are two things that work to impede a deviation. One is that the income realizations are worse (in the sense of first order stochastic dominance). But, more importantly, the shirking worker ends up with higher material payoff than all others, as redistribution guarantees him a higher income, but they make no effort. The "social preferences" make this worker "feel bad" enough about this that she does not want to deviate. In the equilibrium with no effort nobody wants to deviate. Any deviator would end up with a lower final utility than the others (there would be redistribution which guarantees equal income, but the deviator incurs the effort cost), and agents have the same utility already without a deviation.

\subsection{Control treatments}

We also introduce three control treatments:

EXCLUSION: In this treatment only those subjects who choose effort in the first stage can vote for redistribution in the second stage, the decision being taken by majority rule between them. Those who choose NO effort are excluded from redistribution and receive $y^{L}$. A necessary condition for the existence of the all effort equilibrium is $A>y^{L}{ }^{8}$ This equilibrium exists if players have constant relative risk aversion with an Arrow-Pratt risk aversion coefficient $r \geq 0.1$.

We run this extension in order to get more evidence on whether the rich indicate that they like to redistribute only to those who choose effort and then are poor.

After redistribution all individuals of the redistributive pool are equal, unlike in the main treatment where because of sunk cost if there is redistribution the poor who do not choose effort are the richest. We also look at this with the no-effort treatment below.

\footnotetext{
${ }^{8}$ It is still a weakly dominant strategy to vote No if rich, and Yes if poor.
} 
UNANIMITY: In this case redistribution takes place only if all vote Yes. If all agents have the same preferences, then only one equilibrium exists. The high equilibrium exists if $\frac{2}{3} u\left(y^{H}-c\right)+\frac{1}{3} u\left(y^{L}-c\right)>u\left(y^{L}\right)$.

This all effort equilibrium ${ }^{9}$ exists if players have constant relative risk aversion with an Arrow-Pratt risk aversion coefficient $r \geq 0$ (that is, if agents' risk aversion is no higher than with logarithmic preferences).

NO-EFFORT: In this treatment there is no effort stage and wages are determined randomly, while voting takes place according to majority rule. Alternatively one can think of this treatment as modeling a situation in which effort is costless, and thus a strictly dominant strategy. The unique undominated equilibrium in the stage game is that the rich will vote $N o$ and the poor will vote Yes for redistribution. With just one equilibrium in the stage game, there is only one equilibrium in the repeated game.

The point of running this extension is that here being rich depends only on luck, which should make redistribution less of an "ethical" issue. Additionally, it allows us to test whether the fact that agents who made effort in the main treatment end up, under redistribution, with ex-post utility lower than other agents (they have the same money and they made effort) has any impact on the possibility of achieving redistribution.

\section{Experimental design}

Sessions were run at a PC pool (LeeX) in the Department of Economics and Business at Universitat Pompeu Fabra, Barcelona, in November 2004, January and February 2005 and May 2010. In 2004 students were notified via posters within the university and had to sign up on a list at the door of the laboratory. In 2005 and 2010 students could sign in through on-line recruiting system, ORSEE. All sessions were computerized, using a program done with z-tree (Fischbacher 2007). Students were seated in a random order at PCs. Instructions in Spanish (see Supplementary Material for English translation) were then read aloud and questions were answered in private. Throughout the sessions students were not allowed to communicate and could not see others' screens.

The basic design is the following:

The experiment consisted of two stages, an effort stage and a voting stage. In the effort stage all subjects within the same group had to decide whether or not to choose effort. After everybody had decided, those who did not choose effort received a fixed payoff $(L=30)$ and those who chose effort had to pay a cost of 20 and participated in a random lottery, independently drawn for each subject, which determined a high $(H=100)$ or a low $(L=30)$ income with probability $p=2 / 3$ of event $H$ happening. This is, the lottery that they buy by making effort is: $\langle H=100, L=30 ; p(H)=$ $2 / 3\rangle$.

In the second stage, subjects had to vote for or against equal redistribution of the total sum of income to all their members. After the first stage, and before voting,

${ }^{9}$ Again, with voting determined by the weakly dominant strategy to vote No if rich, and Yes if poor. 
It is Hobbes, not Rousseau: an experiment on voting and redistribution

Table 1 The different treatments. Each session generates 2 independent observations

\begin{tabular}{llllll}
\hline Treatment & Effort & Voting Rule & Who Votes & \# of sessions & \# of subjects \\
\hline Effort/majority & YES & Majority & all & 5 & 90 \\
Effort/unanimity & YES & Unanimity & all & 3 & 54 \\
Effort/exclusion & YES & Majority & those who choose effort & 3 & 54 \\
No Effort/majority & NO & Majority & all & 3 & 54
\end{tabular}

subjects were informed of the number of subjects who chose effort, the number of rich (with $H$ income), the total sum to be equally distributed if there were enough votes for redistribution, the individual income if there were no redistribution (excluding costs), the individual income if there were redistribution (excluding costs), and the cost of effort.

The main treatment is as the basic treatment with majority voting in the second stage. We will call this effort-majority treatment. We also introduce the 3 control treatments exposed in Sect. 3.2: (1) Effort-exclusion majority rule, (2) Effort-unanimity rule and (3) No-effort-majority rule

In each session there were two separate groups of 9 subjects each. Each group of the same subjects interacted together for 50 periods according to the rules of one of the above treatments. No subject could participate in more than one session. We run 5 sessions of the effort-majority rule (thus 10 independent observations), 3 sessions of the effort-unanimity rule (6 observations), 3 session of effort-exclusion majority rule (6 observations), and 3 session of no effort-majority rule (6 observations). At the end of the experiment one period was chosen randomly (the same for all subjects of a session) and each subject was paid according to the points he earned in that period with an exchange rate of 2 points $=1$ Euro. This set up was chosen in order to minimize the effect of self-insurance. This is, if in a repeated game agents could insure across time (say, by saving, or by receiving a payoff equal to the average across periods), they would not need to vote for redistribution. Since our intention was to test for the possibility of social insurance (this is, across people, not across time), we opted for eliminating this possibility. Table 1 summarizes the different sessions with the number of participating subjects.

Moreover, this choice does not alter the theoretical equilibria. Clearly, it does not change the equilibrium structure of the static game, since any period can be chosen. But it does not eliminate either the repeated game equilibrium. For such an equilibrium to exist, what is needed is a belief that a "wrong" action in a particular period switches the actions in the remaining periods, and that in those periods the expected payoffs change with those actions. But since the period chosen for actual payoffs is unknown at any point in time, the expected future payoffs for the subjects are still subject to change with the chosen actions. There may be a problem with this setup if the agents did not understand well the probabilistic structure of the payoffs. But behavior seems to be pretty consistent and reasonable during the game, so we do not think this is an important issue.

The payment for each subject was on average 30 Euros including the show up fee. Each session lasted about 1 1/2 hours. 


\section{Behavior of the experimental subjects}

We summarize the behavior of the experimental subjects in two tables and four figures. ${ }^{10}$ Table 2 shows the main results of each session of each treatment pooled over all periods. Table 3 shows the average results within a treatment (plus a distinction between high and low redistribution groups in the main treatment, to be explained below). In Fig. 1 we present a graphical representation of the time evolution of each of the groups of the main treatment (Effort/Majority voting). In Figs. 2, 4 and 3 we present the time evolution of all groups in the Exclusion, No-Effort and Unanimity treatments respectively. In this section we interpret these results and answer our main research question: Do agents behave in a manner consistent with Markovian equilibrium? Is there scope to sustain Rousseaunian equilibrium? ${ }^{11}$

\subsection{Effort/majority voting}

Looking at the averages inside groups (Table 2) in the main treatment (with effort stage and majority voting) is easy to observe that some groups have high effort and no redistribution (groups 1, 3 and 10) while the rest have low effort and redistribution. In the high effort groups more than $80 \%$ of the agents exert effort, while redistribution seldom occurs. In the remaining 7 sessions, the effort levels converge to those of the low effort equilibrium. Aggregate effort levels are typically far below $50 \%$ with one exception of $60 \%$ (see first column of Table 2). These two sets of groups correspond to the two equilibria of the stage game.

A high level of effort tends to produce a high number of rich individuals (remember that people choosing to make effort get the high level of income with $\frac{2}{3}$ probability) and high levels of aggregate income in this experiment are associated with low redistribution levels. More precisely, when the majority of the players is poor in a given period, redistribution took place $90 \%$ of the time across all periods and groups. When the majority was rich, redistribution occurred $15 \%$ of the time. Across all groups the majority was poor in $74.6 \%$ of all periods.

The poor vote overwhelmingly in favor of redistribution in all groups, with some quantitatively small (but sometimes statistically significant) differences between different subgroups of poor people. For example, there is a difference in YES votes between poor individuals who chose no effort $(91 \%)$ and those who chose effort (86\%) (see Table 3, effort majority). This difference is significant at the 0.055 level using a binomial test, since in 8 out of all 10 groups no effort choosers show higher propensity to vote yes than effort choosers. There is also a statistical difference between those poor individuals who chose to make no effort in the two different kinds of effort groups (99-100\% vote YES in groups with high average effort level, 83\% vote YES in groups with low average effort level) with a value of $U=21, p=0.008$. There is, on the other hand, no statistically significant difference in voting patterns between those poor individuals who chose to make effort in the two different kinds

\footnotetext{
${ }^{10}$ In Appendix $\mathrm{C}$ we report the distribution of Payoff in the different treatments.

${ }^{11}$ The total expected payoff if all agents make effort is $76.66=1 / 3 * 30+2 / 3 * 100$.
} 
It is Hobbes, not Rousseau: an experiment on voting and redistribution

Table 2 Averages for all groups

\begin{tabular}{|c|c|c|c|c|c|c|}
\hline \multirow[t]{2}{*}{ Group \# / treatment } & (1) & & & & & \\
\hline & $\%$ effort & $\% \mathrm{red} / \mathrm{rich}$ & $\%$ red/poor & $\% \mathrm{red} / \mathrm{no}$ eff. & $\%$ red & exp pay \\
\hline 01 Effort - Majority & 0.87 & 0.12 & 0.97 & 1.00 & 0.46 & 52.91 \\
\hline 02 Effort-Majority & 0.34 & 0.07 & 0.68 & 0.90 & 0.92 & 37.82 \\
\hline 03 Effort-Majority & 0.81 & 0.07 & 0.82 & 1.00 & 0.32 & 53.80 \\
\hline 04 Effort-Majority & 0.60 & 0.24 & 1.00 & 0.85 & 0.76 & 44.71 \\
\hline 05 Effort-Majority & 0.18 & 0.22 & 0.65 & 0.74 & 0.76 & 33.49 \\
\hline 06 Effort-Majority & 0.20 & 0.1 & 0.77 & 0.82 & 0.8 & 35.33 \\
\hline 07 Effort-Majority & 0.31 & 0.28 & 0.87 & 0.86 & 0.96 & 38.51 \\
\hline 08 Effort-Majority & 0.34 & 0.15 & 0.93 & 0.96 & 0.98 & 37.47 \\
\hline 09 Effort-Majority & 0.48 & 0.03 & 0.93 & 0.97 & 0.78 & 43.36 \\
\hline 10 Effort-Majority & 0.82 & 0.024 & 0.99 & 0.99 & 0.36 & 51.82 \\
\hline 01 Effort-Unanimity & 0.73 & 0.21 & 0.75 & 0.91 & 0 & 51.11 \\
\hline 02 Effort-Unanimity & 0.77 & 0.33 & 0.91 & 0.87 & 0 & 48.53 \\
\hline 03 Effort-Unanimity & 0.73 & 0.17 & 0.85 & 0.94 & 0 & 50.51 \\
\hline 04 Effort-Unanimity & 0.79 & 0.25 & 0.80 & 0.91 & 0 & 50.20 \\
\hline 05 Effort-Unanimity & 0.79 & 0.29 & 0.98 & 0.98 & 0 & 49.76 \\
\hline 06 Effort-Unanimity & 0.80 & 0.11 & 0.93 & 0.91 & 0 & 49.27 \\
\hline 01 Effort-Exclusion & 0.97 & 0.3 & 0.95 & n.a. & 0.62 & 54.40 \\
\hline 02 Effort-Exclusion & 0.95 & 0.19 & 0.94 & n.a. & 0.34 & 54.80 \\
\hline 03 Effort-Exclusion & 0.95 & 0.20 & 0.97 & n.a. & 0.44 & 54.80 \\
\hline 04 Effort-Exclusion & 0.93 & 0.34 & 0.94 & n.a. & 0.56 & 56.73 \\
\hline 05 Effort-Exclusion & 0.98 & 0.07 & 0.97 & n.a. & 0.35 & 53.6 \\
\hline 06 Effort-Exclusion & 0.97 & 0.23 & 0.99 & n.a. & 0.39 & 57.4 \\
\hline 01 No Effort & n.a. & 0.22 & 0.76 & n.a. & 0.32 & 74.33 \\
\hline 02 No Effort & n.a. & 0.2 & 0.87 & n.a. & 0.18 & 79.62 \\
\hline 03 No Effort & n.a. & 0.21 & 0.90 & n.a. & 0.22 & 58.06 \\
\hline 04 No Effort & n.a. & 0.04 & 0.96 & n.a. & 0.08 & 58.22 \\
\hline 05 No Effort & n.a. & 0.17 & 0.98 & n.a. & 0.16 & 58.22 \\
\hline 06 No Effort & n.a. & 0.19 & 0.98 & n.a. & 0.31 & 58.66 \\
\hline
\end{tabular}

Columns:

(1) Percentage of agents exerting effort (unconditional)

(2) Percentage of votes for redistribution conditional on the agent being rich

(3) Percentage of votes for redistribution conditional on the agent being poor

(4) Percentage of votes for redistribution conditional on the agent having made no effort in first stage

(5) Percentage of votes for redistribution (unconditional)

(6) Average pay-off

of groups (93\% vote YES in groups with high average effort level, $83 \%$ in vote YES groups with high average effort level).

The rich, on the other hand, vote overwhelmingly against redistribution. They also show a slightly different behavior in the different subgroups: in groups with high average effort levels $7 \%$ of them vote YES and in the low effort groups $16 \%$ vote YES. 
A. Cabrales et al.

Table 3 Treatment averages. Separating high-low effort groups in main treatment

\begin{tabular}{lllllll}
\hline & $\begin{array}{l}(1) \\
\% \text { effort }\end{array}$ & $\begin{array}{l}(2) \\
\% \text { red/rich }\end{array}$ & $\begin{array}{l}(3) \\
\% \text { red/poor }\end{array}$ & $\begin{array}{l}\text { \% red/no eff. } \\
\text { \% red }\end{array}$ & $\begin{array}{l}\text { (6) } \\
\text { exp pay }\end{array}$ \\
\hline Effort-Majority-HE & 0.83 & 0.07 & 0.93 & 1.00 & 0.38 & 52.84 \\
Effort-Majority-LE & 0.35 & 0.16 & 0.83 & 0.87 & 0.85 & 38.67 \\
Effort-Majority & 0.49 & 0.13 & 0.86 & 0.91 & 0.71 & 42.92 \\
Effort-Unanimity & 0.77 & 0.23 & 0.87 & 0.92 & 0.00 & 49.90 \\
Effort-Exclusion & 0.96 & 0.22 & 0.96 & n.a. & 0.45 & 55.29 \\
No Effort & n.a. & 0.17 & 0.91 & n.a. & 0.21 & 57.5 \\
Total & 0.64 & 0.19 & 0.88 & 0.90 & 0.51 & 46.67 \\
\hline
\end{tabular}

This is significantly different on a $9 \%$ level $(U=16.5)$. Notice, however, that the differences between any two subgroups of rich people is much smaller than between a given subgroup of rich compared to any subgroup of poor people. In any case this is the reverse than you would expect in the "Rousseaunian" equilibrium. ${ }^{12}$

The small differential behavior of different subgroups, together with the different initial conditions on effort, may explain the different behavior over time in different sessions, which we discuss below.

We summarize these facts in:

Observation 1 The rich and the poor are clearly distinguished in their behavior. The poor people typically vote YES, and the rich typically vote NO with only slight differences in the different groups.

\subsubsection{Behavior over time. Convergence to equilibria}

In Fig. 1 we show, for every one of the 10 independent groups, the effort choice, the number of poor subjects and the number of yes votes for redistribution. These numbers are averaged over the 9 subjects in the group and over blocks of 5 consecutive periods. We also show, for each group, the proportion of periods in each block of 5 when there was redistribution (note that this is a number between 0 and 1 ).

We see two distinct patterns:

1. There are three groups $(1.1,2.1$ and 5.2) which maintain high average levels of effort ( 7.8 to 8.6 out of 9 subjects in the three groups) with relatively low levels of redistribution ( $32 \%$ to $46 \%$ averaged over all periods).

2. There are 6 groups which in the first periods of the experiment have intermediate levels of effort (3.8 to 6.8 out of 9) and in the final periods have low levels effort (less than 2 out of 9). These groups also have high levels of redistribution during the whole time ( $76 \%$ to $98 \%$ across the 6 groups). In one of these groups (group 5.1), it looks like there was an unsuccessful attempt to revert to a situation with

\footnotetext{
${ }^{12}$ We can presume that this pattern of voting arises from the fact that in low effort groups there are more poor agents, thus providing partial support for some type of social preferences.
} 


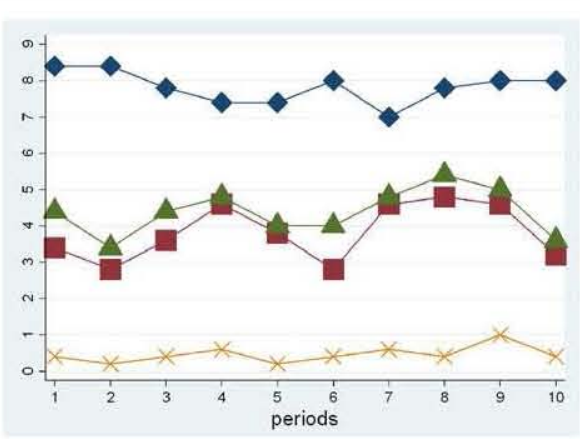

(a) Effort-Majority (1.1)

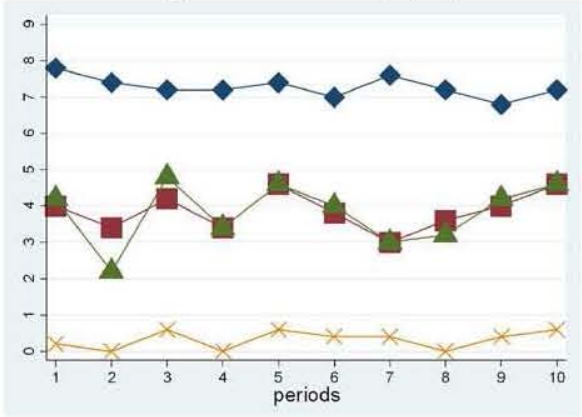

(c) Effort-Majority (2.1)

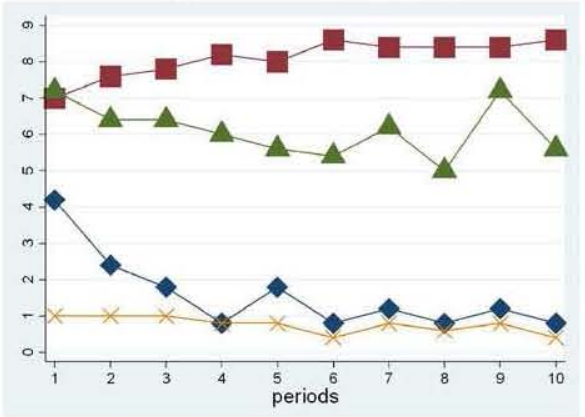

(e) Effort-Majority (3.1)

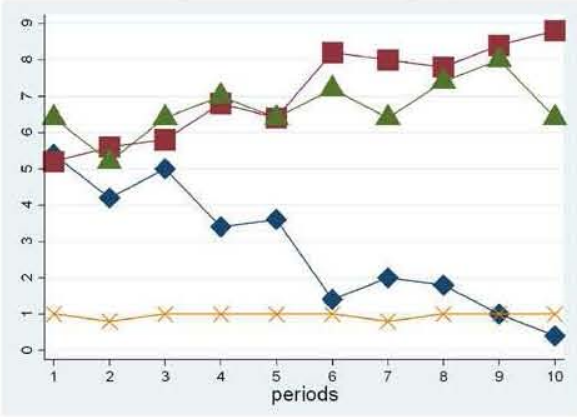

Fig. 1 Tin (g) Effort-Majority.(4.1) groups

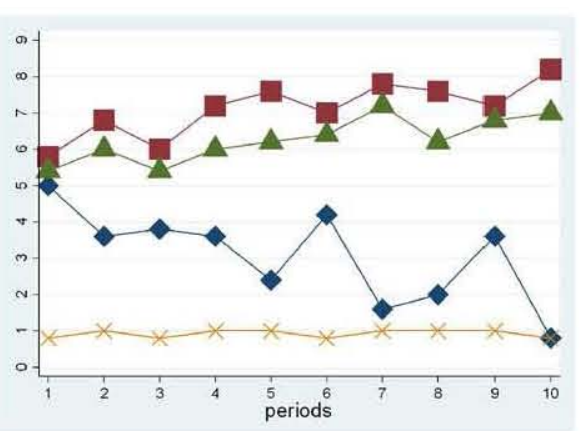

(b) Effort-Majority (1.2)

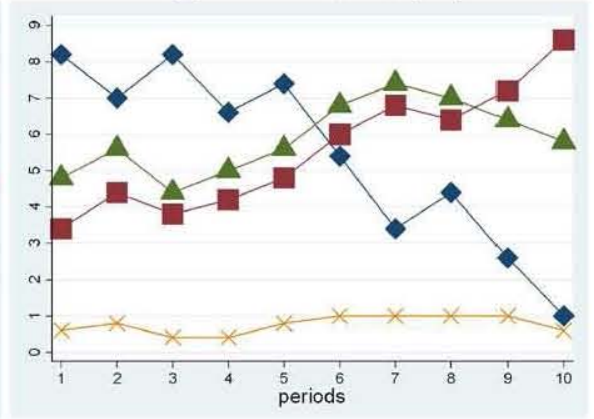

(d) Effort-Majority (2.2)

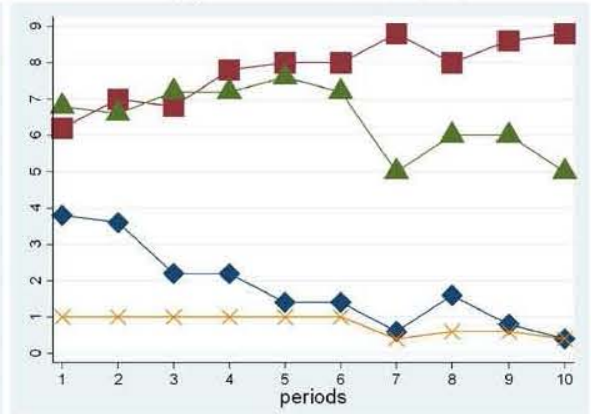

(f) Effort-Majority (3.2)

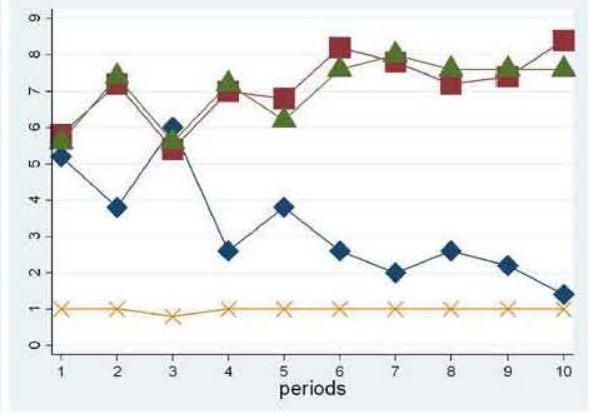

(h) Effort-Majority (4.2) 


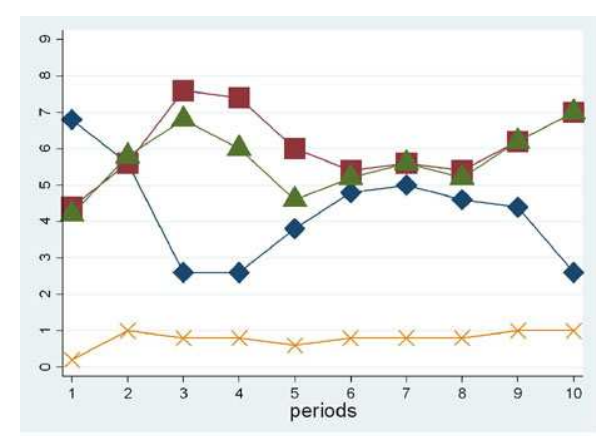

(i) Effort-Majority (5.1)

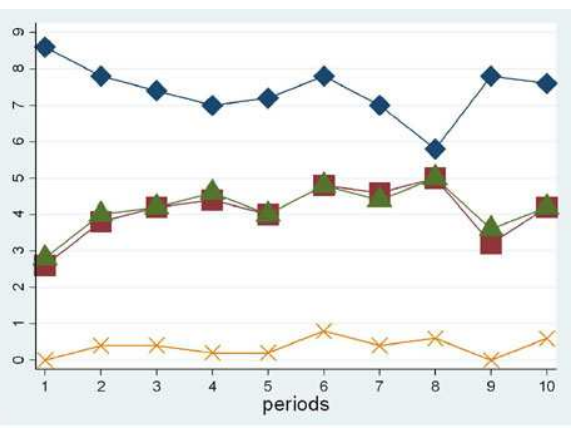

(j) Effort-Majority (5.2)

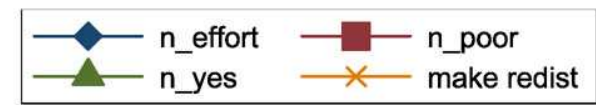

Fig. 1 (Continued)

higher effort levels. An additional group (group 2.2) started out with a high effort level (8.2) and nevertheless ended up with low effort and high redistribution.

We summarize these facts in:

Observation 2 In the majority of groups (7/10) behavior in the final periods is similar to the low effort equilibrium with high redistribution, but we also see some groups whose behavior in the final periods is similar to the high effort equilibrium with low redistribution. There are no groups whose behavior is similar to the ("Rousseaunian") equilibrium with high effort and high redistribution.

The initial condition seems to explain whether final behavior looks more like one or the other equilibrium. In Table 2 we report average effort levels, as well as the voting patterns for the rich, the poor who made effort, and the poor who did not make effort. We also report on that table the average redistribution levels for each single group and across all sessions of every treatment. Comparing the initial effort level at the beginning of the session (first five periods), we observe in the high effort sessions an average effort level of 8.26, while it is 5.51 in the sessions with low effort in the final periods. This difference is significant different at the 0.02 level $(U=20)$, using Wilcoxon-Mann-Whitney U test. We obtain a similar result by comparing the initial redistribution level in the high effort sessions (0.2) and in the remaining session (0.8). The difference is significant also at $p=0.02$ (for $U=20$ ).

We summarize these facts in:

Observation 3 Initial behavior of effort seems to be one driving force explaining the behavior in the final periods. The higher is the initial effort in a group, the more likely is that group to end in the high-effort/no-redistribution equilibrium. The less initial effort in the group, the more likely is that group to end up in the low-effort/highredistribution equilibrium. 


\subsubsection{Hobbes vs. Rousseau: what determines the voting of the rich?}

Thus, we have seen that the behavior of the agents after a learning period is consistent with the set of equilibria in the stage game, while there is no group whose collective behavior is consistent with the non-Markov first best equilibrium that we have deemed "Rousseaunian".

This is clear indication that agents are not conditioning their votes in payoff irrelevant information. In particular, a notorious salient feature of the "Rousseaunian" non-Markov behavior is that the vote of rich agents should depend on the degree of effort exerted by poor agents, as they vote for redistribution in order to punish the misbehaving agents and to revert to a situation with no redistribution. From Observation 1 we know that an agent's vote depends critically on whether she is rich or poor and marginally on whether she exerted effort or not. Now we intend to test directly if the voting behavior depends on the degree of effort realized by the poor agents. If it does not, there is no scope for non-Markov behavior.

We do so using Tables 4 and 5. In both tables we present results investigating under which circumstances an individual votes in favor of redistribution in our main [base-line] treatment. Table 4 runs a probit determining the probability that an individual votes in favor of redistribution for all the individuals and during all the periods. Table 5 does the same but restricting the sample to those agents who were rich when they voted.

The right hand side variables are characteristics of the individual and of the state of the economy during the period:

- "largeperiod" is a dummy that takes value 1 if the number of times that the agents have played is larger than 15 , that is, after agents have had time to learn how the other agents are playing.

- "ipooreffort" and "irich" are dummies that determine the type that the agent has when she votes.

- "ipooreffort" takes value 1 if the agent has made effort but is unlucky.

- "irich" takes the value 1 if the agent has made the effort, and she is "rich". Thus, the reference group are the agents who made no effort.

- " $n$-effort", "redistpast" and " $n$-effortpast" look at general characteristics of the economy at the time of the vote which are known to the agent.

- " $n$-effort" is the number of agents who did make effort in the current period.

- "redistpast" is a dummy that takes value 1 if there was redistribution in the previous period.

- " $n$-effortpast" is the number of agents who made effort the previous period.

- "ratio-effort-poor" is the ratio of the number of poor who made effort to the total number of poor.

- Finally we introduce control for individual effects and session effects in the form of dummies for each individual and for each session. We also control for the vote of the agents in the previous period with the variable "pastvote".

Table 4 presents the results for all individuals and periods. Column (1) reports the results with controls for individual heterogeneity, while column (2) presents the results without individual dummies. Not surprisingly the larger effect corresponds to 
Table 4 Probit on voting for redistribution. All agents, main treatment

\begin{tabular}{|c|c|c|c|c|c|c|}
\hline $\begin{array}{l}\text { All Sample, } \\
\text { Main Treatment }\end{array}$ & (1) & (2) & (3) & (4) & (5) & (6) \\
\hline largeperiod & $\begin{array}{c}0.109 \\
(0.074)\end{array}$ & $\begin{array}{c}0.111 \\
(0.069)\end{array}$ & $\begin{array}{c}0.109 \\
(0.094)\end{array}$ & $\begin{array}{c}0.111 \\
(0.087)\end{array}$ & $\begin{array}{c}0.107 \\
(0.074)\end{array}$ & $\begin{array}{c}0.107 \\
(0.069)\end{array}$ \\
\hline ipooreffort & $\begin{array}{l}-.393^{* * *} \\
(0.104)\end{array}$ & $\begin{array}{l}-.479^{* * *} \\
(0.09)\end{array}$ & $\begin{array}{l}-.393^{*} \\
(0.218)\end{array}$ & $\begin{array}{l}-.479^{* *} \\
(0.226)\end{array}$ & $\begin{array}{l}-.386^{* * *} \\
(0.104)\end{array}$ & $\begin{array}{l}-.453^{* * *} \\
(0.09)\end{array}$ \\
\hline irich & $\begin{array}{c}-3.424^{* * *} \\
(0.106)\end{array}$ & $\begin{array}{c}-3.215^{* * *} \\
(0.088)\end{array}$ & $\begin{array}{l}-3.424^{* * *} \\
(0.318)\end{array}$ & $\begin{array}{c}-3.215^{\text {*** }} \\
(0.287)\end{array}$ & $\begin{array}{c}-3.418^{* * *} \\
(0.107)\end{array}$ & $\begin{array}{c}-3.196^{* * *} \\
(0.088)\end{array}$ \\
\hline$n$-effort & $\begin{array}{l}0.279^{* * *} \\
(0.026)\end{array}$ & $\begin{array}{l}0.267^{* * *} \\
(0.024)\end{array}$ & $\begin{array}{l}0.279^{* * *} \\
(0.044)\end{array}$ & $\begin{array}{l}0.267^{* * *} \\
(0.042)\end{array}$ & $\begin{array}{l}0.28^{* * *} \\
(0.026)\end{array}$ & $\begin{array}{l}0.267^{* * *} \\
(0.024)\end{array}$ \\
\hline redispast & $\begin{array}{l}0.275^{* * *} \\
(0.073)\end{array}$ & $\begin{array}{l}0.257^{* * *} \\
(0.068)\end{array}$ & $\begin{array}{l}0.275^{* * *} \\
(0.081)\end{array}$ & $\begin{array}{l}0.257^{* * *} \\
(0.07)\end{array}$ & $\begin{array}{l}0.246^{* * *} \\
(0.075)\end{array}$ & $\begin{array}{l}0.212^{* * *} \\
(0.069)\end{array}$ \\
\hline$n$-effortpast & $\begin{array}{c}0.026 \\
(0.022)\end{array}$ & $\begin{array}{c}0.025 \\
(0.021)\end{array}$ & $\begin{array}{c}0.026 \\
(0.026)\end{array}$ & $\begin{array}{c}0.025 \\
(0.023)\end{array}$ & $\begin{array}{c}0.025 \\
(0.022)\end{array}$ & $\begin{array}{c}0.025 \\
(0.021)\end{array}$ \\
\hline pastvote & & & & & $\begin{array}{c}0.115^{*} \\
(0.061)\end{array}$ & $\begin{array}{l}0.203^{* * *} \\
(0.054)\end{array}$ \\
\hline constant & $\begin{array}{l}-.585^{*} \\
(0.351)\end{array}$ & $\begin{array}{l}-.390^{*} \\
(0.209)\end{array}$ & $\begin{array}{l}-.585^{* * *} \\
(0.17)\end{array}$ & $\begin{array}{l}-.390^{* *} \\
(0.156)\end{array}$ & $\begin{array}{l}-.652^{*} \\
(0.354)\end{array}$ & $\begin{array}{l}-.479^{* *} \\
(0.211)\end{array}$ \\
\hline \multicolumn{7}{|l|}{ Marginal effects } \\
\hline largeperiod & 0.039 & 0.04 & 0.039 & 0.04 & 0.039 & 0.039 \\
\hline ipooreffort & $-.147^{* * *}$ & $-.180^{* * *}$ & $-.147^{*}$ & $-.180^{* *}$ & $-.144^{* * *}$ & $-.170^{* * *}$ \\
\hline irich & $-.912^{* * *}$ & $-.890^{* * *}$ & $-.912^{* * *}$ & $-.890^{* * *}$ & $-.911^{* * *}$ & $-.888^{* * *}$ \\
\hline$n$-effort & $0.099^{* * *}$ & $0.095^{* * *}$ & $0.099^{* * *}$ & $0.095^{* * *}$ & $0.099^{* * *}$ & $0.095^{* * *}$ \\
\hline redispast & $0.1^{* * *}$ & $0.094^{* * *}$ & $0.1^{* * *}$ & $0.094^{* * *}$ & $0.089^{* * *}$ & $0.077^{* * *}$ \\
\hline $\begin{array}{l}n \text {-effortpast } \\
\text { pastvote }\end{array}$ & 0.009 & 0.009 & 0.009 & 0.009 & $\begin{array}{l}0.009 \\
0.041^{*}\end{array}$ & $\begin{array}{l}0.009 \\
0.072^{* * *}\end{array}$ \\
\hline Session Controls & $\mathrm{Y}$ & $\mathrm{Y}$ & $\mathrm{Y}$ & Y & $\mathrm{Y}$ & $\mathrm{Y}$ \\
\hline Individual Controls & $\mathrm{Y}$ & $\mathrm{N}$ & $\mathrm{Y}$ & $\mathrm{N}$ & $\mathrm{Y}$ & $\mathrm{N}$ \\
\hline Number of obs & 4312 & 4410 & 4312 & 4410 & 4312 & 4410 \\
\hline Pseudo $R^{2}$ & 0.569 & 0.51 & 0.569 & 0.510 & 0.569 & 0.513 \\
\hline
\end{tabular}

Standard deviations in parenthesis. $\left(^{*}\right)$ coefficients are significant at the $95 \%$ significance level; $\left(^{* *}\right)$ at the $99 \%$ and $(* * *)$ at the $99.9 \%$

rich individuals, who are much less likely to vote for redistribution than anybody else in the economy. Poor agents who made effort are less likely to vote for redistribution than the ones who did not make the effort, but they vote for redistribution with a much larger probability than the rich ones. This might be the consequence of a certain inertia in voting in the equilibrium without redistribution. ${ }^{13}$ The variable $n$-effort has a positive and significant effect, but as we will see below is not because the rich react to it, but because the poor do: the more individuals did effort the more rich there are, and the larger is the cake to share if there is redistribution.

\footnotetext{
${ }^{13}$ Another possibility is that people make effort out of ideological fervor, and this fervor bars some of them from completely enjoying redistribution when they need it.
} 


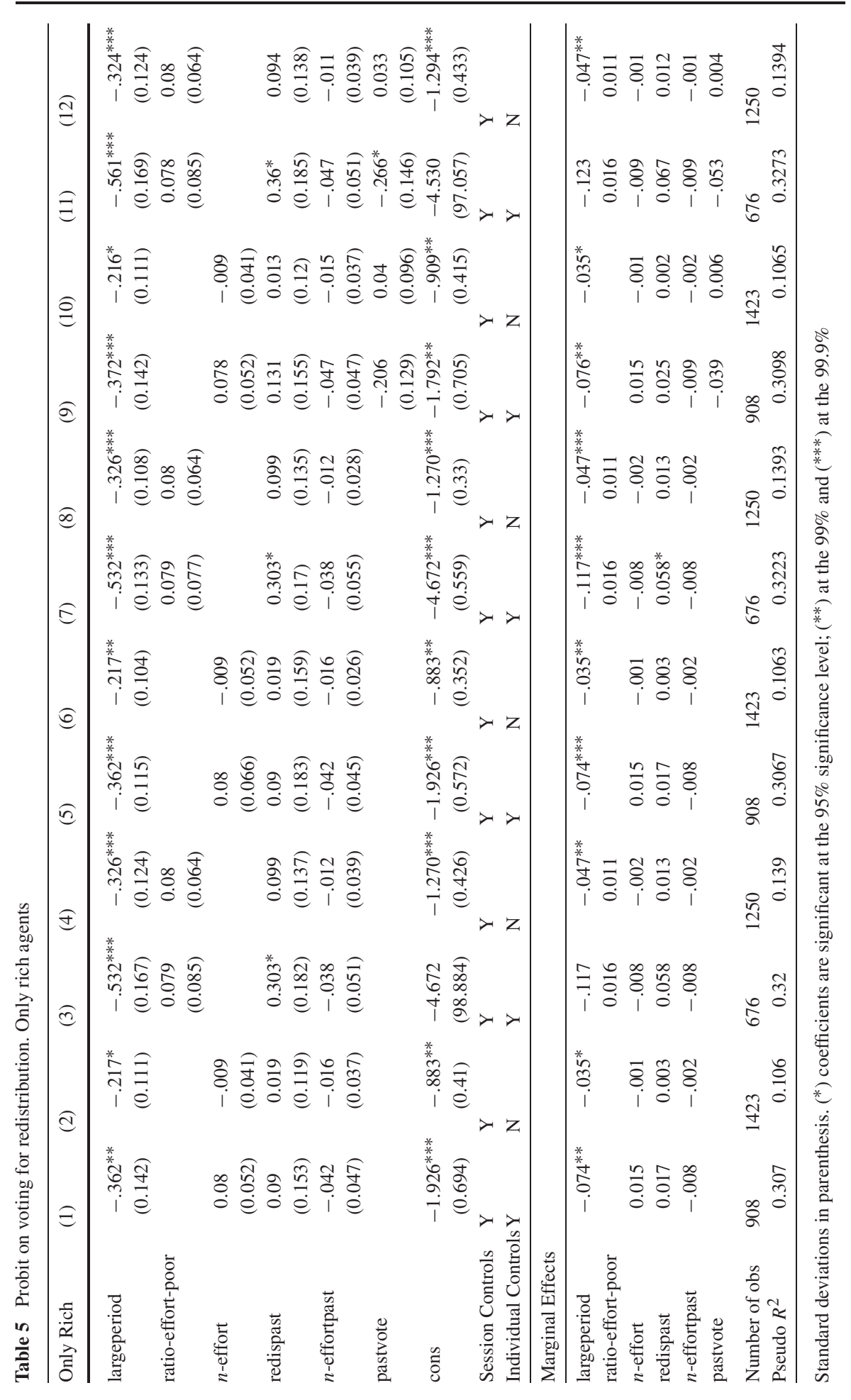


Including the previous period voting decision of the agent as a regressor, or clustering the errors by group does not change these results (see columns (3)-(6) in Table 4).

In Table 5 we address the main issue raised by our experiment: do agents act in a non-Markovian fashion? In such a case we would expect the rich agents to react to the effort made by the poor. That is, if the poor were poor because they were lazy I would not vote for redistribution, but if they were poor out of bad luck I would be more prone to favor redistribution.

Thus, we run a probit to determine the probability of voting for redistribution but restricting our sample to the agents and periods of time when the individuals are rich. That is, we include in the sample only the occasions when individuals were rich, and see if their probability of voting for redistribution depends on the state of the economy. In particular, we see if it depends on the level of effort being exerted by the poor agents. Columns (1) and (3) include individual dummies, and columns (3) and (4) a variable determining the effort exerted by the poor. ${ }^{14}$

Clearly the rich agents do not react to their environment. They do not vote against redistribution because the poor do not make effort: they vote against redistribution because they are rich and the poor would expropriate them from their money (see insignificant coefficient of ratio effort poor). It is Hobbes, not Rousseau, who explains their behavior. The only thing to which they seem to react is the passage of time: once they have learned to play the game, they systematically vote against redistribution, and only in the initial periods there might be a larger probability of voting for redistribution (see significant coefficient for large period). Thus, we can state the following observation:

Observation 4 Rich agents do not condition their vote on the number of poor agents who made effort. After a learning period, voting patterns are consistent with the stage game equilibria: poor vote for redistribution and rich against it, irrespectively on whether the poor arrive to their state via misfortune or via misbehavior. There is no hint of non-Markov behavior.

As in Table 4, the inclusion as a regressor of the previous period voting decision, or clustering the errors by group does not change these results (see colums (3)-(6) in Table 5).

\subsection{Control treatments}

\subsubsection{Exclusion if no effort}

With our exclusion treatment, the rich can vote for a sort of redistribution which helps only the 'deserving' poor. In that treatment the individuals who chose no effort cannot participate in redistribution.

Figure 2 presents the six groups of Effort-exclusion-majority-rule treatment. In Table 2 we display average effort levels, as well as the voting patterns for all individuals across treatments. Effort levels are very high (on average 96\%, compared to $83 \%$ in the high effort groups of the main treatment, a significant difference

\footnotetext{
${ }^{14}$ The number of observations varies because multicolinearity issues induce us to drop many individuals when including individual dummies.
} 


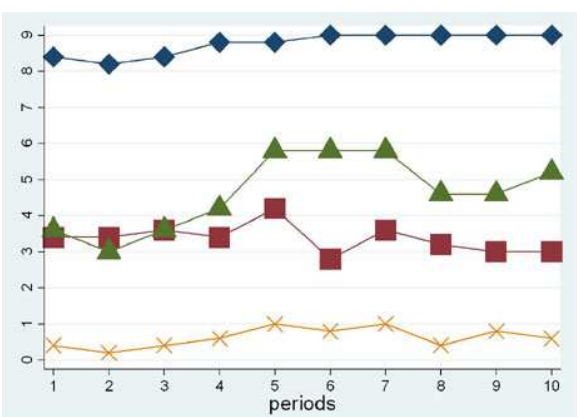

(a) Effort-Exclusion(1.1)

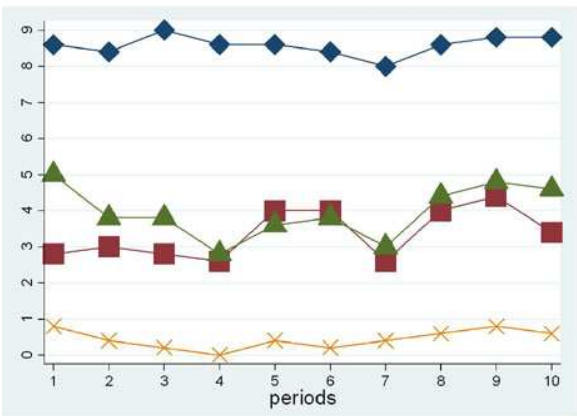

(c) Effort-Exclusion (2.1)

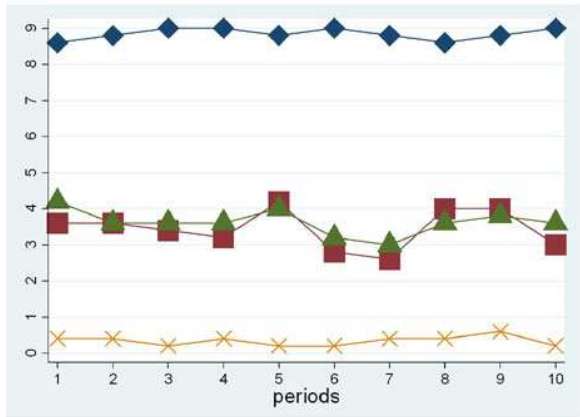

(e) Effort-Exclusion (3.1)

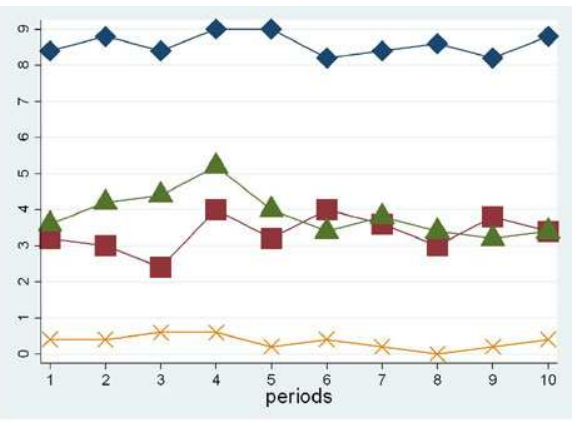

(b) Effort-Exclusion (1.2)

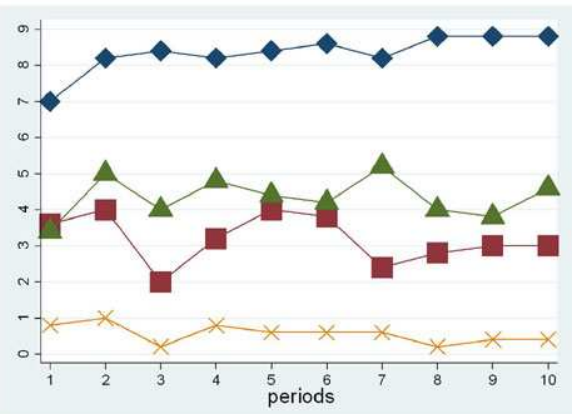

(d) Effort-Exclusion (2.2)

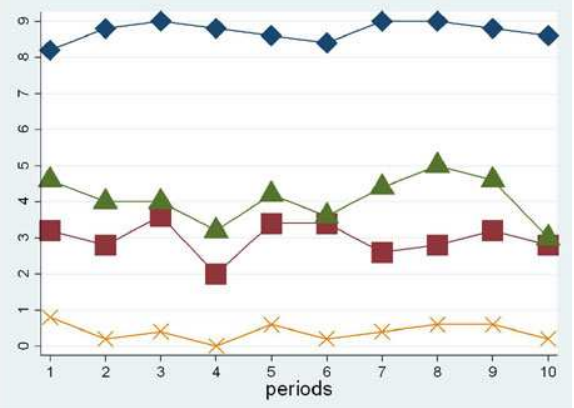

(f) Effort-Exclusion (3.2)

$$
\begin{array}{lll|}
\longrightarrow \text { n_effort } & \text { n_poor } \\
\sim & \text { n_yes } & \text { make redist }
\end{array}
$$

Fig. 2 Time series of effort exclusion groups

with $U=18, p=0.01$ ). Redistribution is $45 \%$ on average, ranging from $34 \%$ to $62 \%$ in the different groups. This is similar to the redistribution in the high effort groups of our main treatment, which is $38 \%{ }^{15}$ and very different from the level of redistribution-85\%-in the low effort groups of the main treatment.

\footnotetext{
${ }^{15}$ The difference is not statistically significant. Note, however, the low number of observations.
} 
The proportion of rich people who vote YES is $22 \%$ across periods, which is significantly different from the proportion of the main treatment with high effort $(7 \%)$ $(U=16.5$ and $p=0.023)$. Comparing the voting patterns of the rich people in the low effort groups of the main treatment $(16 \%)$ and their behavior in this treatment $(22 \%)$, there is not a significant difference with $U=28.5, p=0.14$. The proportion of YES votes of the rich is still very far from that of the poor in the low effort groups of the main treatment (over $80 \%$ ) or in this treatment (over $90 \%$ ).

Notice that if there is a treatment where "Rousseaunian" behavior has a good environment, it is here. By construction, in this treatment redistribution would treat differently those among the poor who misbehaved from those who were unfortunate. In spite of this, $75 \%$ of the rich individuals vote against redistribution. There seems to be little empathy towards the unfortunate.

Observation 5 Even when the rich players can control who benefits from redistribution, a large majority of them still dislike redistribution. However, a few individuals prefer redistribution when they can control who benefits (the YES votes increase from $13 \%$ in the main treatment to $22 \%$ in this one).

The difference in the proportion of yes votes by the rich between treatments can be explained by the fact that in the majority game, voting no is the only way to sustain a high effort equilibrium outside the Rousseaunian world (where we cannot be, by our empirical result above). In the exclusion (and unanimity, see below) worlds, redistribution is a "consumption" good, you do it because you like it, not to sustain an equilibrium. It can be done for "fairness" reasons (see Alesina and Angeletos 2005; Bolton and Ockenfels 2000, or Fehr and Schmidt 1999).

\subsubsection{Unanimity}

A treatment where redistribution requires an unanimous agreement, is useful to check how much effort is made when subjects cannot be involuntarily expropriated. In this case, the final utility does not depend essentially on other people's decision, so the main consideration for whether an individual should make effort or not is her degree of risk aversion (high effort implies choosing a lottery with high mean and high dispersion).

Figure 3 shows the six groups of the unanimity rule treatments. The average effort level $(77 \%)$ is significantly lower than in the high effort groups of the main treatment (83\%) with $U=12, p=0.03$. It is also significantly lower than in the exclusion treatment $(95 \%)$, with $U=44$ and $p=0.005$. There is no redistribution in any period. There is no difference in the proportion of YES votes by the rich between the exclusion treatment $(26 \%)$ and the unanimity treatment $(23 \%)$. As pointed out before, since a player can always impede redistribution, to choose to make effort indicates a low degree of risk aversion.

Across all groups the rich typically do not vote for redistribution (the averages range between $7 \%$ to $25 \%$ in the different treatments). Thus, it seems clear that the rich do not vote against redistribution because they dislike laziness. Instead, they do not want to contribute to the poor, independently of the cause of poverty. On the other hand, the poor independently of their effort agree on voting YES to redistribution (ranging from $82 \%$ to $95 \%$ on average). 


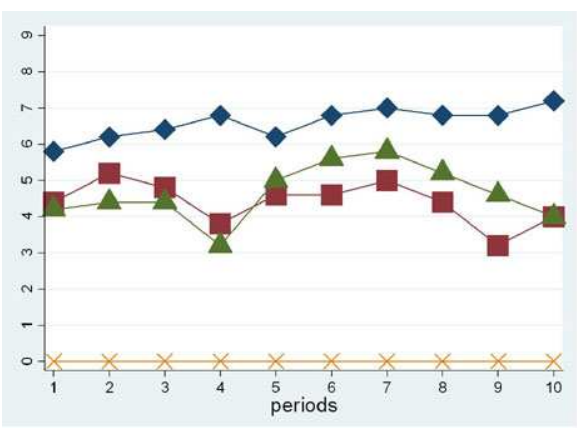

(a) Unanimity(1.1)

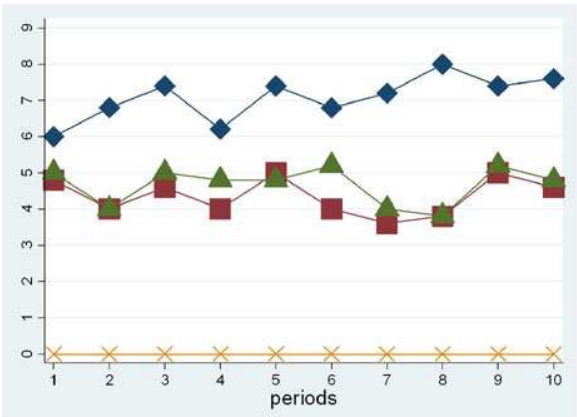

(c) Unanimity (2.1)

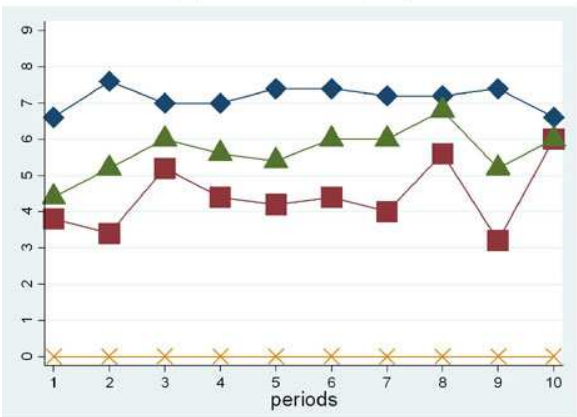

(e) Unanimity (3.1)

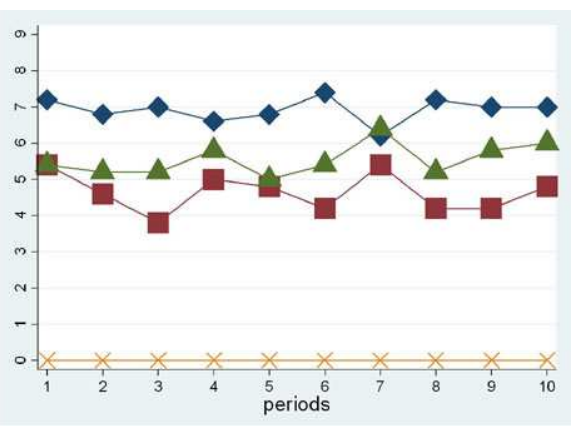

(b) Unanimity (1.2)

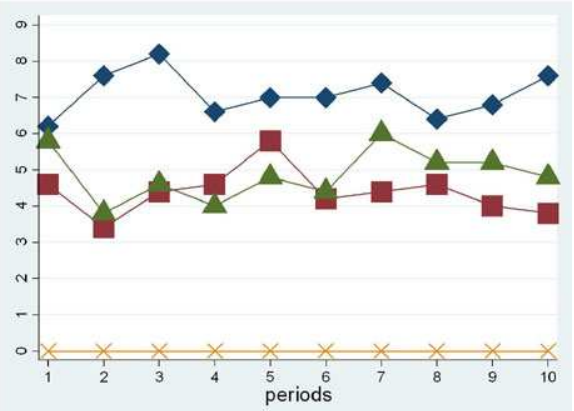

(d) Unanimity (2.2)

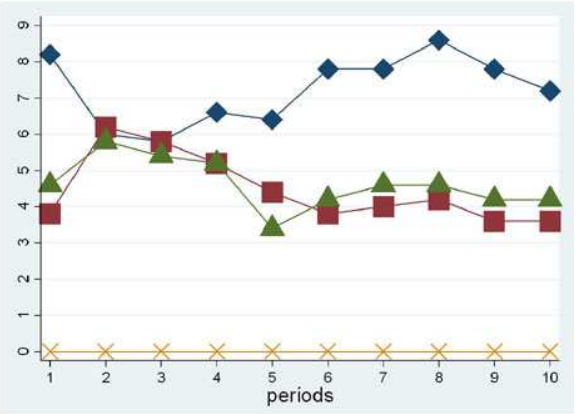

(f) Unanimity (3.2)

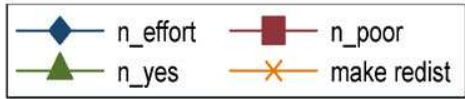

Fig. 3 Time series of unanimity groups

\subsubsection{No effort}

With the no effort treatment, wealth is the result of a purely random outcome over which individuals have no control. So the poor are in such a state because they were unlucky, not because they were dishonest. Under these circumstances Rousseau might expect individuals to be more prone to help one another. However, it is not an equilibrium to do so when players do not have other-regarding preferences. 


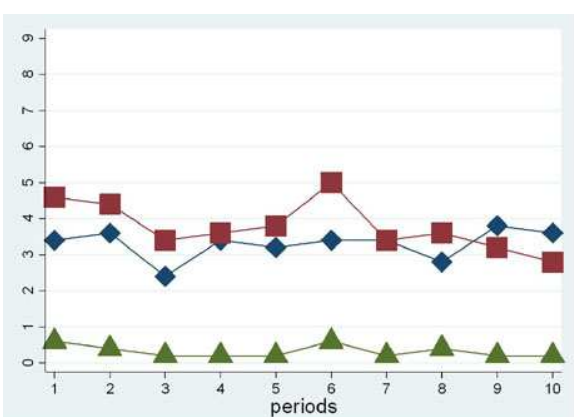

(a) No-Effort(1.1)

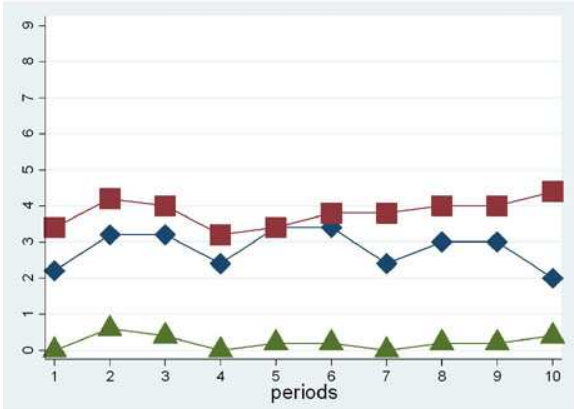

(c) No-Effort (2.1)

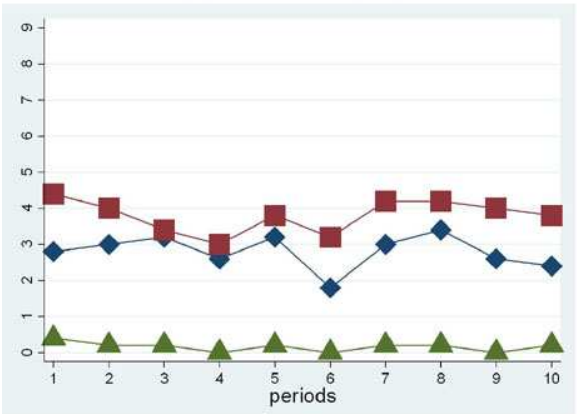

(e) No-Effort (3.1)

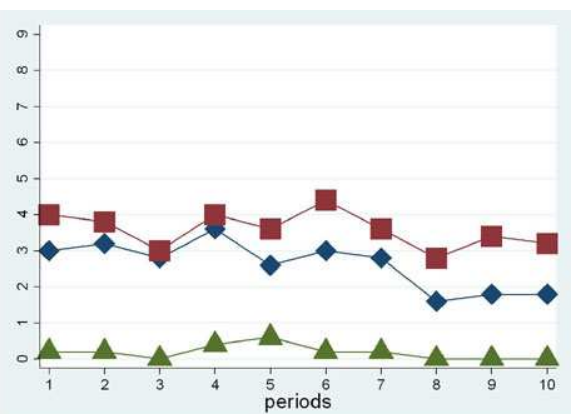

(b) No-Effort (1.2)

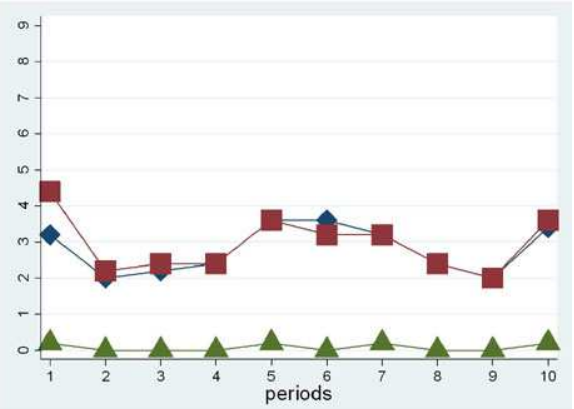

(d) No-Effort (2.2)

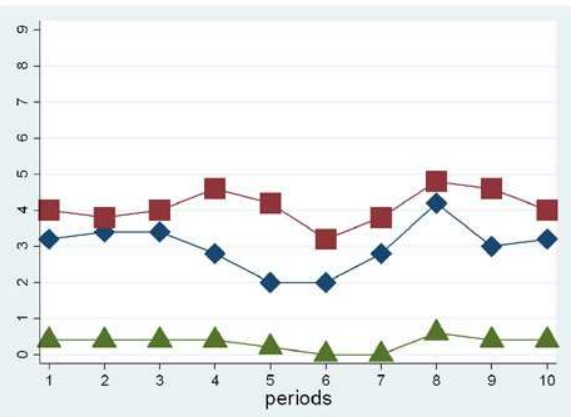

(f) No-Effort (3.2)

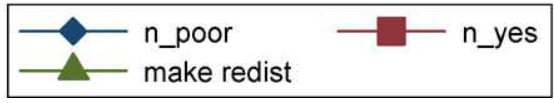

Fig. 4 Time series of no-effort groups

Figure 4 shows the six No effort-majority groups. On average redistribution occurs $21 \%$ of the time and $17 \%$ of the rich and $91 \%$ of the poor vote YES. Thus, also in this treatment the rich do not show much compassion for poor people. Notice that we mentioned that an important reason for this treatment was to test whether the fact that agents who made effort in the main treatment end up, under redistribution, with expost utility lower than other agents (they have the same money and they made effort) has any impact the possibility of achieving redistribution. The answer is clearly that 
it does not make much difference (YES votes by the rich increase only from $13 \%$ to $17 \%)$.

\subsubsection{Determinants of voting in the control treatments}

In Sect. 5.1.2 we presented regressions showing that the Rich agents do not condition their vote on the number of poor agents who made effort. After a learning period, voting patterns are consistent with the stage game equilibria. In the appendix we show the results of analogous regressions for the additional treatments. The results in most cases are basically the same. ${ }^{16}$ The only mildly puzzling result is what happens in the treatment with exclusion, where the rich do not seem to be biased against redistribution (the point estimate is still negative, but insignificant). In addition the $n \_$effort variable has a negative and significant coefficient. As we said when discussing the descriptive statistics of this treatment, redistribution is a "consumption" good in that environment. Subjects can do it because they like it, not to sustain an equilibrium. Hence, it is natural that the behavior does not respond to the same determinants.

\section{Conclusions}

The main result of this paper is that our experimental subjects behave so that rich subjects vote against redistribution and poor vote for redistribution, independently of the rule linking voting to allocations or the reasons for poverty. This rules out a "Rousseaunian" equilibrium with effort and redistribution. And even a static equilibrium with effort but without redistribution is fragile in the lab. Hence, the incentive and efficiency issues of our laboratory welfare state are large.

In our game it is theoretically possible to sustain an equilibrium where everybody makes effort, and where everybody who is unlucky gets help from the lucky ones, what we call a Rousseaunian equilibrium. Its enforcement would be possible via a strategy relying in the (credible) punishment of reverting to the (bad) Hobbesian equilibrium. Our results show that this equilibrium is not reached. When there is effort in our experiments, redistribution is not sustained over time. This result arises in one of two ways. In three of our main treatment sessions with high initial effort, the rich did not want to redistribute from the beginning. One other session (session 2 , group 2) started with high effort and high redistribution, but behavior converged to the equilibrium with low effort. We interpret this as implying that there is no social contract binding the destinies of rich and poor. The rich simply do not feel indebted to the deserving poor. Instead, our subject groups either reach the equilibrium with high effort and no redistribution, or the one with low effort and nothing to redistribute.

In our design, the redistribution, when it happens, is complete. Would the Rich be willing to tolerate partial redistribution? One answer comes from our control treatments. Rich subjects vote against redistribution, independently of the rule linking voting to allocations or the reasons for poverty. We see no good reason why they would

\footnotetext{
${ }^{16} \mathrm{We}$ decided against running joint regressions with treatment dummies because the environments are so different that the effect of the independent variables could (and indeed does) change between treatments and in some case those variables do not even exist (think e.g. of the treatments without effort).
} 
behave differently under partial redistribution. To this reasoning, one could reply that in reality there is some redistribution, most of the time partial. We strongly believe that our experimental results point to other reasons for the existence of redistribution. Perhaps the threat of revolution, or other disruptive forms of redistribution, explains the existence of redistribution, as Acemoglu and Robinson (2000) have forcefully argued. This seems to us a better explanation for this phenomenon than a Rousseaunian pact, which our evidence rejects.

A reading of our results can be that if a society has an encompassing welfare state, then its presence must have strong effects on efficiency. And conversely, if a society does not provide a generous redistribution system, it is probably because its political institutions prevent the "poor" from getting enough political leverage.

From a technical point of view our results can be read as indicating that, at least when confronting politico-economic situations, agents tend to disregard non payoff relevant events. The outcomes of the game thus constitute Markov perfect equilibria. This is good news for the large macroeconomic literature that has dealt with the issue, as it has almost in its totality concentrated on Markov perfect equilibria.

This paper is a first step in an experimental investigation of the political economy of redistribution in a context with effort decisions and multiple equilibria. But there are some important issues that we have left behind. For example, in our framework the "effort" decision consists basically on the choice of a lottery with a cost. This may not yield the same sense of entitlement that effort normally conveys in real life. More research would help to clarify this point.

It would also be important to determine to which extent agents behave rationally in voting on inter-temporal issues. More precisely, an important issue is to determine whether people take into account the effect of their vote on the future distribution of rich and poor, and how this future distribution will affect the future outcome of the political game. We intend to answer that question in a follow-up paper.

\section{Appendix A: Proof of Proposition 1}

Proof As a first step, notice that, in the voting stage of the game, it is weakly dominant to vote $v_{i}=Y$ when $y_{i}=y^{L}$ and $v_{i}=N$ when $y_{i}=y^{H}$. The reason is that the vote affects the final payoff only if the voter is pivotal. In that case, voting $Y$ rather than $N$ shifts the outcome from $y_{i}=y^{L}$ to $\sum_{j=1}^{n} y_{j} / 9$ when poor and from $y_{i}=y^{H}$ to $\sum_{j=1}^{n} y_{j} / 9$ when rich.

Then, we need to check first that $e_{i}=e^{H}$ is a best-response in the first period when $e_{j}=e^{H}$ for all $j \in N, j \neq i$. This is indeed true as, in that case, the expected payoff from choosing $e_{i}=e^{H}$ is $A$ whereas the payoff from choosing $e_{i}=e^{L}$ is $B$ and by assumption $A>B$.

Finally, we need to check that $e_{i}=e^{L}$ is a best-response in the first period when $e_{j}=e^{L}$ for all $j \in N, j \neq i$. This is indeed true as, in that case, the expected payoff from choosing $e_{i}=e^{H}$ is $C$ whereas the payoff from choosing $e_{i}=e^{L}$ is $y^{L}$ and by assumption $C<u\left(y^{L}\right)$. In one of them $e_{i}=e^{H}$ for all $i \in N$ and in the other one $e_{i}=e^{L}$ for all $i \in N$. In both equilibria, for all $i \in N, v_{i}=Y$ when $y_{i}=y^{L}$ and $v_{i}=N$. 


\section{Appendix B: Proof of Proposition 2}

Proof The strategies that sustain the equilibrium are as follows:

I $\gamma_{i}\left(h^{t-1}\right)=\left(e^{H}, Y\right) \forall t \leq 50-K-1$, if for all $\tau \leq t-1$ there was no unilateral deviation from $\left(e^{H}, Y\right)$.

II $\gamma_{i}\left(h^{t-1}\right)=\left(e^{H}, N\right) \forall t>50-K-1$, if for all $\tau \leq 50-K-1$ there was no unilateral deviation from $\left(e^{H}, Y\right)$.

III $\gamma_{i}\left(h^{t-1}\right)=\left(e^{L}, Y\right)$, otherwise.

Obviously the strategies prescribe equilibrium actions after histories in II and III, as they are static (and unconditional) equilibria of the stage game. In histories like I the strategies prescribe equilibrium actions since a deviation implies a gain of $D-E$ with respect to the equilibrium action, but a loss of at least $K\left(A-y^{L}\right)$ afterward. Then the deviation is not optimal since $D-E<K\left(A-y^{L}\right)$ by assumption.

\section{Appendix C: Payoffs}

We now show how the differences in behavior across treatments and equilibria impact the distribution of payoffs.

Obviously, in the low-effort groups of the main treatment we find the lowest inequality (standard deviation is on average 13.01) while in the high-effort groups the inequality is much higher (standard deviation is 25.64). The highest inequality can be found in the Unanimity and in the No effort treatments (standard deviations are 31.32 and 28.55 respectively). The inequality of the Exclusion treatment is not significantly different from that of the high effort groups of the main treatment (standard deviation is 24.95 ).

In terms of average monetary payoffs, the richest groups are those in the Exclusion treatment (55.18) and in the No effort treatment (76.98). The numbers are not comparable strictly speaking, as in the No effort sessions the subjects can get the "good" lottery without paying an effort cost. But even if we subtracted the effort cost (say because effort was compulsory and not a decision) to make the numbers comparable, we still would have an average of 56.98 .

Unanimity produces slightly worse average payoffs (49.90) than in the high effort groups in the Effort-majority rule treatments (52.84) and both are much better than in the low effort groups of that same treatment (38.67).

\section{Appendix D: Empirical analysis of other treatments}

Tables 6, 7 and 8 report the analysis as in Table 4 for treatments other than our main one. and Tables 9, 10 and 11 report the analysis as in 5 . 
A. Cabrales et al.

Table 6 Probit on voting for redistribution. All sample, effort-exclusion

Standard deviations in parenthesis. $\left(^{*}\right)$ coefficients are significant at the $95 \%$

significance level; (**) at the $99 \%$ and $(* * *)$ at the $99.9 \%$

Table 7 Probit on voting for redistribution. All sample, effort-unanimity

Standard deviations in parenthesis. $\left({ }^{*}\right)$ coefficients are significant at the $95 \%$ significance level; $(* *)$ at the $99 \%$ and $(* * *)$ at the $99.9 \%$

\begin{tabular}{lcc}
\hline All Sample, Effort-Exclusion & $(1)$ & $(2)$ \\
\hline largeperiod & -.042 & -.052 \\
& $(0.081)$ & $(0.072)$ \\
ipooreffort & -3.859 & -3.490 \\
& $(157.848)$ & $(80.488)$ \\
irich & -6.972 & -6.146 \\
& $(157.848)$ & $(80.488)$ \\
$n$-effort & $-.123^{*}$ & -.095 \\
& $(0.065)$ & $(0.059)$ \\
redispast & $0.243^{* * *}$ & $0.172^{* * *}$ \\
& $(0.075)$ & $(0.066)$ \\
$n$-effortpast & 0.049 & 0.058 \\
& $(0.064)$ & $(0.057)$ \\
cons & 6.535 & 5.891 \\
& $(157.850)$ & $(80.490)$ \\
Session Controls & $\mathrm{Y}$ & $\mathrm{Y}$ \\
Individual Controls & $\mathrm{Y}$ & $\mathrm{N}$ \\
Number of obs & 2646 & 2646 \\
Pseudo $R^{2}$ & 0.579 & 0.462 \\
\hline
\end{tabular}

All Sample, Effort-Unanimity

(2)

\begin{tabular}{lcc}
\hline largeperiod & 0.115 & $0.144^{* *}$ \\
& $(0.077)$ & $(0.067)$ \\
ipooreffort & -.169 & $-.255^{* *}$ \\
& $(0.121)$ & $(0.1)$ \\
irich & $-2.560^{* * *}$ & $-2.195^{* * *}$ \\
& $(0.116)$ & $(0.088)$ \\
$n$-effort & -.002 & 0.007 \\
& $(0.034)$ & $(0.028)$ \\
redispast & & \\
& & \\
$n$-effortpast & 0.009 & 0.012 \\
& $(0.031)$ & $(0.027)$ \\
cons & $2.368^{* * *}$ & $0.98^{* * *}$ \\
& $(0.541)$ & $(0.285)$ \\
Session Controls & $\mathrm{Y}$ & $\mathrm{Y}$ \\
Individual Controls & $\mathrm{Y}$ & $\mathrm{N}$ \\
Number of obs & 2499 & 2646 \\
Pseudo $R^{2}$ & 0.520 & 0.378 \\
\hline
\end{tabular}


It is Hobbes, not Rousseau: an experiment on voting and redistribution

\begin{tabular}{|c|c|c|c|}
\hline \multirow{2}{*}{$\begin{array}{l}\text { Table } 8 \text { Probit on voting for } \\
\text { redistribution. All sample, no } \\
\text { effort }\end{array}$} & All Sample, No Effort & (1) & (2) \\
\hline & largeperiod & 0.004 & 0.011 \\
\hline & & $(0.075)$ & $(0.068)$ \\
\hline & ipooreffort & $2.675^{* * *}$ & $2.315^{* * *}$ \\
\hline & & $(0.081)$ & $(0.071)$ \\
\hline & irich & & \\
\hline & $n$-effort & & \\
\hline & redispast & -.060 & -.037 \\
\hline & & $(0.087)$ & $(0.077)$ \\
\hline & $n$-effortpast & & \\
\hline & cons & -.169 & $-.880^{* * *}$ \\
\hline & & $(0.208)$ & $(0.091)$ \\
\hline & Session Controls & $\mathrm{Y}$ & $\mathrm{Y}$ \\
\hline $\begin{array}{l}\text { Standard deviations in } \\
\text { parenthesis. }\left(^{*}\right) \text { coefficients are }\end{array}$ & Individual Controls & $\mathrm{Y}$ & $\mathrm{N}$ \\
\hline significant at the $95 \%$ & Number of obs & 2646 & 2646 \\
\hline significance level; $\left({ }^{* *}\right)$ at the & Pseudo $R^{2}$ & 0.539 & 0.405 \\
\hline
\end{tabular}

Table 9 Probit on voting for redistribution. Only rich agents, effort-exclusion

\begin{tabular}{lcccc}
\hline Only Rich, Effort-Exclusion & $(1)$ & $(2)$ & $(3)$ & $(4)$ \\
\hline largeperiod & -.087 & -.091 & 0.077 & 0.081 \\
ratio-effort-poor & $(0.094)$ & $(0.079)$ & $(0.2)$ & $(0.162)$ \\
& & & $-.470^{* * *}$ & $-.326^{* * *}$ \\
$n$-effort & & & $(0.09)$ & $(0.069)$ \\
& $-.211^{* * *}$ & $-.151^{* *}$ & & \\
redispast & $(0.072)$ & $(0.063)$ & & $0.417^{* *}$ \\
& $0.318^{* * *}$ & $0.205^{* * *}$ & $0.514^{* *}$ & $(0.169)$ \\
$n$-effortpast & $(0.087)$ & $(0.073)$ & $(0.218)$ & 0.069 \\
& 0.018 & 0.053 & 0.043 & $(0.116)$ \\
cons & $(0.072)$ & $(0.062)$ & $(0.14)$ & -.160 \\
& 0.662 & 0.345 & -.349 & $(0.999)$ \\
Session Controls & $(0.864)$ & $(0.715)$ & $(1.277)$ & $\mathrm{Y}$ \\
Individual Controls & $\mathrm{Y}$ & $\mathrm{Y}$ & $\mathrm{Y}$ & $\mathrm{Y}$ \\
Number of obs & $\mathrm{Y}$ & $\mathrm{N}$ & & 381 \\
Pseudo $R^{2}$ & 1397 & 1682 & 283 & 0.136 \\
\hline
\end{tabular}

Standard deviations in parenthesis. $\left(^{*}\right)$ coefficients are significant at the $95 \%$ significance level; $\left(^{* *}\right)$ at the $99 \%$ and $(* * *)$ at the $99.9 \%$ 
A. Cabrales et al.

Table 10 Probit on voting for redistribution. Only rich agents, effort-unanimity

\begin{tabular}{lcccc}
\hline Only Rich, Effort-Unanimity & $(1)$ & $(2)$ & $(3)$ & $(4)$ \\
\hline largeperiod & 0.117 & $0.17^{*}$ & 0.144 & $0.18^{*}$ \\
& $(0.123)$ & $(0.089)$ & $(0.133)$ & $(0.096)$ \\
ratio-effort-poor & & & $-.150^{* *}$ & $-.117^{* *}$ \\
& & & $(0.068)$ & $(0.048)$ \\
$n$-effort & 0.027 & 0.022 & & \\
& $(0.054)$ & $(0.037)$ & & \\
redispast & & & & \\
& & & & \\
$n$-effortpast & -.055 & 0.012 & -.053 & 0.016 \\
& $(0.051)$ & $(0.036)$ & $(0.055)$ & $(0.038)$ \\
cons & 0.834 & $-1.670^{* * *}$ & 0.927 & $-1.340^{* * *}$ \\
& $(0.927)$ & $(0.407)$ & $(1.053)$ & $(0.33)$ \\
Session Controls & $\mathrm{Y}$ & $\mathrm{Y}$ & $\mathrm{Y}$ & $\mathrm{Y}$ \\
Individual Controls & $\mathrm{Y}$ & $\mathrm{N}$ & $\mathrm{Y}$ & $\mathrm{N}$ \\
Number of obs & 804 & 1339 & 731 & 1221 \\
Pseudo $R^{2}$ & 0.348 & 0.035 & 0.364 & 0.045 \\
\hline
\end{tabular}

Standard deviations in parenthesis. $\left(^{*}\right)$ coefficients are significant at the $95 \%$ significance level; $\left({ }^{* *}\right)$ at the $99 \%$ and $(* * *)$ at the $99.9 \%$

Table 11 Probit on voting for redistribution. Only rich agents, no effort

\begin{tabular}{|c|c|c|c|c|}
\hline Only Rich, No Effort & (1) & (2) & (3) & (4) \\
\hline largeperiod & $\begin{array}{l}-.109 \\
(0.101)\end{array}$ & $\begin{array}{l}-.078 \\
(0.08)\end{array}$ & $\begin{array}{l}-.370^{* *} \\
(0.163)\end{array}$ & $\begin{array}{l}-.255^{* *} \\
(0.128)\end{array}$ \\
\hline ratio-effort-poor & & & $\begin{array}{c}-2.137^{* * *} \\
(0.515)\end{array}$ & $\begin{array}{c}-1.184^{* * *} \\
(0.399)\end{array}$ \\
\hline$n$-effort & & & & \\
\hline redispast & $\begin{array}{l}-.175 \\
(0.118)\end{array}$ & $\begin{array}{l}-.089 \\
(0.09)\end{array}$ & $\begin{array}{c}0.114 \\
(0.174)\end{array}$ & $\begin{array}{c}0.115 \\
(0.135)\end{array}$ \\
\hline$n$-effortpast & & & & \\
\hline cons & $\begin{array}{l}0.676^{* * *} \\
(0.254)\end{array}$ & $\begin{array}{l}-.760^{* * *} \\
(0.102)\end{array}$ & $\begin{array}{c}-3.373^{* * *} \\
(0.594)\end{array}$ & $\begin{array}{c}-1.565^{* * *} \\
(0.322)\end{array}$ \\
\hline Session Controls & $\mathrm{Y}$ & Y & $\mathrm{Y}$ & $\mathrm{Y}$ \\
\hline Individual Controls & $\mathrm{Y}$ & $\mathrm{N}$ & $\mathrm{Y}$ & $\mathrm{N}$ \\
\hline Number of obs & 1410 & 1795 & 526 & 592 \\
\hline Pseudo $R^{2}$ & 0.354 & 0.038 & 0.397 & 0.023 \\
\hline
\end{tabular}

Standard deviations in parenthesis. $\left(^{*}\right)$ coefficients are significant at the $95 \%$ significance level; $\left({ }^{* *}\right)$ at the $99 \%$ and $(* * *)$ at the $99.9 \%$ 


\section{References}

Acemoglu, D., \& Robinson, J. (2000). Why did the west extend the franchise? Democracy, inequality, and growth in historical perspective. The Quarterly Journal of Economics, 115(4), 1167-1199.

Alesina, A., \& Angeletos, G.-M. (2005). Fairness and redistribution. American Economic Review, 95, 960-980.

Atkinson, A. B. (1995). The welfare state and economic performance. National Tax Journal, 48, 171-198.

Attanasio, O., Banks, J., \& Tanner, S. (2002). Asset holding and consumption volatility. Journal of Political Economy, 110(4), 771-792.

Berninghaus, S. K., \& Ehrhart, K. M. (1998). Time horizon and equilibrium selection in Tacit coordination games: experimental results. Journal of Economic Behavior \& Organization, 37, 231-248.

Binmore, K. (1998). Just playing: game theory and the social contract II. Cambridge: MIT Press.

Bolton, G., \& Ockenfels, A. (2000). ERC: a theory of equity, reciprocity, and competition. American Economic Review, 90, 166-193.

Fehr, E., \& Schmidt, K. M. (1999). A theory of fairness, competition and cooperation. The Quarterly Journal of Economics, 114, 817-868.

Fiorina, M. P., \& Plott, C. R. (1978). Committee decisions under majority rule: an experimental study. The American Political Science Review, 72, 575-598.

Fischbacher, U. (2007). z-Tree: Zurich toolbox for ready-made economic experiments. Experimental Economics, 10, 171-178.

Frohlich, N., \& Oppenheimer, J. A. (1990). Choosing justice in experimental democracies with production. The American Political Science Review, 84, 461-477.

Hassler, J., Rodríguez Mora, J. V., Storesletten, K., \& Zilibotti, F. (2003). The survival of the welfare state. American Economic Review, 93, 1-26.

Hoffman, E., \& Spitzer, M. L. (1985). Entitlements, rights and fairness: an experimental examination of subjects' concepts of distributive justice. Journal of Legal Studies, 14, 259-297.

Lindbeck, A., Nyberg, S., \& Weibull, J. (1999). Social norms and economic incentives in the welfare state. The Quarterly Journal of Economics, 114, 1-35.

Moller, S., Huber, E., Stephens, J. D., Bradley, D., \& Nielsen, F. (2003). Determinants of relative poverty in advanced capitalist democracies. American Sociological Review, 68, 22-51.

Ochs, J. (1995). Coordination problems. In A. Roth \& J. Kagel (Eds.), Handbook of experimental economics. Princeton: Princeton University Press.

Plott, C. R. (1982). Industrial organization theory and experimental economics. Journal of Economic Literature, 20, 1485-1527.

Porteous, D. (1783). A letter to the citizens of Glasgow. Glasgow: Robert Chapman, Alexander Duncan (p. 12).

Schram, A. (2005). Artificiality: the tension between internal and external validity in economic experiments. Journal of Economic Methodology, 12, 225-238.

Schram, A., \& Sonnemans, J. (1996). Why people vote: experimental evidence. Journal of Economic Psychology, 17, 417-442.

Sutter, M. (2002). Public bad prevention by majority voting on redistribution: experimental evidence group decision and negotiation. Group Decision and Negotiation, 11, 415-428.

Sutter, M., Kocher, M. G., \& Haigner, S. (2010). Choosing the stick or the carrot? Endogenous institutional choice in social dilemma situations. Review of Economic Studies, 77, 1540-1566.

Sutter, M., \& Weck-Hannemann, H. (2004). An experimental test of the public-goods crowding-out hypothesis when taxation is endogenous. FinanzArchiv: Public Finance Analysis, 60, 94-110.

Tyran, J.-R., \& Sausgruber, R. (2006). A little fairness may induce a lot of redistribution in democracy. European Economic Review, 50, 469-485.

Van Huyck, J. B., Battalio, R. C., \& Beil, R. O. (1990). Tacit coordination games, strategic uncertainty, and coordination failure. American Economic Review, 80, 234-248. 